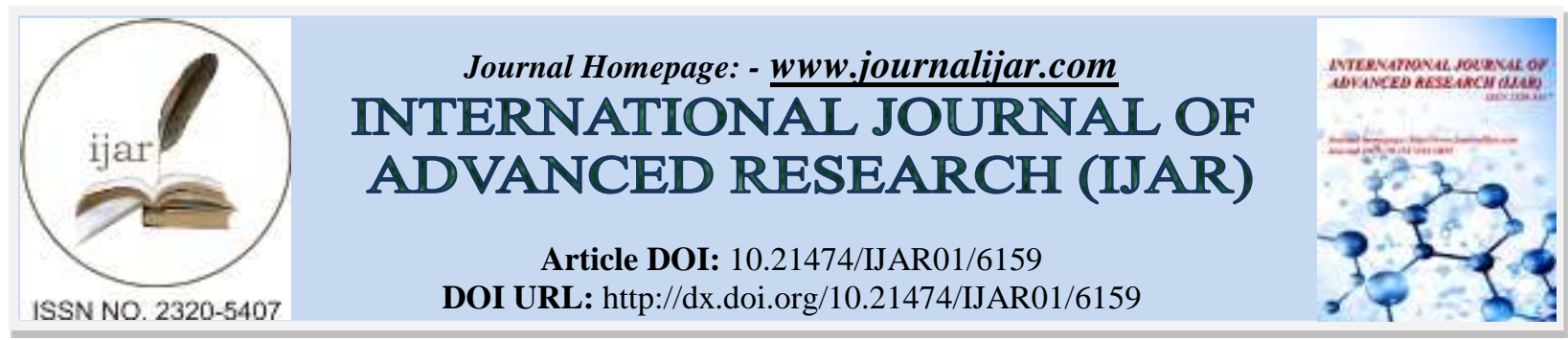

RESEARCH ARTICLE

\title{
A CROSS SECTIONAL STUDY OF VITAMIN D LEVEL IN PATIENTS WITH GESTATIONAL DIABETES MELLITUS ATTENDING ANTE-NATAL CARE AT KING ABDUL AZIZ UNIVERSITY HOSPITAL, JEDDAH.
}

Duaa M. Abdulmajeed ${ }^{1}$, Azra Kirmani ${ }^{2}$, Ayman A. Bukhari ${ }^{3}$, Kholoud A. Ghamri ${ }^{4}$ and Sawsan M. R. Ali ${ }^{5}$.

1. Graduate student, Department of Physiology, Faculty of Medicine, King Abdul Aziz University.

2. Assistant Professor of Physiology, Faculty of Medicine, King Abdul Aziz University.

3. Assistant Professor of Obstetrics and Gynaecology, Faculty of Medicicne, King Abdul Aziz University.

4. Assistant Professor of Internal Medicine, Faculty of Medicine, King Abdul Aziz University.

5. Professor of Physiology, Faculty of medicine, King Abdul Aziz University.

\section{Manuscript Info}

Manuscript History

Received: 24 October 2017

Final Accepted: 26 November 2017

Published: December 2017

\section{Abstract}

Background: Vitamin D is part of many physiological functions in the body. This is enough reason to optimise vitamin D level in the body. Studies have linked vitamin D deficiency to the development of Gestational Diabetes Mellitus (GDM). We aimed to compare Vitamin D levels in GDM and Non GDM pregnant women at King Abdulaziz University Hospital Jeddah, Kingdom of Saudi Arabia.

Methods: This cross-sectional study was conducted at Obstetrics and Gynaecology outpatient clinic and inpatient obstetrics ward at King Abdulaziz University hospital, Jeddah, Saudi Arabia from January to April 2016. 92 subjects who fulfilled the inclusion criteria were enrolled in the study.

Results: Vitamin D level in both the GDM \& non GDM groups showed no statistically significant difference. All the 92 female patients were distributed into four quartiles depending on vitamin $\mathrm{D}$ level. ,30.4\% of quartile 4 was GDM while $47.8 \%$ of quartile 1 was GDM with no statistical significance. The mean age in the GDM group was $31.9 \pm 4.8$ and in the non GDM was $26.9 \pm 5.6$ which was statistically significant $(\mathrm{p}=0.001)$. The mean score of BMI in GDM group was $32.3 \pm 5.8$ and non GDM was $28.3 \pm 5.5$ which was statistically significant $(\mathrm{p}=0.002)$. No statistically significant difference was found among the two groups as per the following parameters: Gestational Age (GA), gravity \& parity.

Conclusion: We found no statistical difference between the GDM and Non GDM groups as regards Vitamin D. Subjects with higher BMI and higher age had significantly higher incidence of GDM. When the results were arranged according to quartiles with lowest vitamin D in quartile 1 and highest vitamin D in quartile 4 , we found that the number of GDM cases in the first quartile were double ( $\mathrm{N}=12-47.8 \%)$ than the number of GDM cases in the fourth quartile ( $\mathrm{N}=6-30.4 \%)$ this difference did not show a statistical significance.

Copy Right, IJAR, 2017,. All rights reserved.

Corresponding Author:- Duaa M. Abdulmajeed.

Address:- Graduate student, Department of Physiology, Faculty of Medicine, King Abdul Aziz 


\section{Introduction and Aim of the Study:-}

Vitamin D is part of many physiological functions in the body. This is enough reason to optimise vitamin D level in the body. Deficiency of vitamin D is prevalent Worldwide. Vitamin D level is a global health issue that has been recognized as a vital indicator of the health status of an individual. Deficiency of vitamin D is one of the commonest endocrine conditions in the world. (Qari, 2013).

Although Saudi Arabia is a tropical country where there is abundant sunshine throughout the year, the problem of vitamin D deficiency has been widely increasing. Vitamin D deficiency has been studied in Saudi Arabian population with percentage ranging from 28\%-100\% (Sadat-Ali, 2009, Dr. Ebtehal Solaiman Al-Mogbel, 2012).

The prevalence of vitamin D deficiency in pregnancy is high, with potential major consequences for mother and foetus (Baker et al., 2012, Mutlu et al., 2015). Studies have linked vitamin D deficiency to the development of Gestational Diabetes Mellitus (GDM) (Parildar et al., 2013, Zuhur et al., 2013, Pleskacova et al., 2015, Shahgheibi et al., 2016).

The evidence provided by studies which indicate that vitamin D levels increase to a very high-level in the first trimester indicates the importance of Vitamin D. The source of vitamin D in both the mother and the foetus is the maternal blood. Vitamin D receptors are found in abundance in the placenta and various other maternal organs (Hollis and Wagner, 2017a, Hollis and Wagner, 2017b, Janyne Althaus, August 2011).

Vitamin D plays an important immunomodulatory role in preventing foetal rejection by the mother (Hollis and Wagner, 2017a). It influences the trophoblast anti-inflammatory and anti-microbial responses (Hollis and Wagner, 2017b, Urrutia-Pereira and Solé, 2015). Vitamin D has been shown to play a role in the prevention of preeclampsia, and preterm births (McDonnell et al., 2017, Bodnar et al., 2015, Zhou et al., 2017). Vitamin D deficiency was found in insulin resistance and gestational diabetes (Shahgheibi et al., 2016). It plays a vital role in the normal skeletal growth of the foetus(Hollis and Wagner, 2017b).

Pregnancy is a very crucial stage of the future generation with lasting implications on the health of the baby and its future. One of the most common conditions we come across in mothers during pregnancy is GDM, its prevalence in Saudi Arabia ranges from $12.5 \%$ to $36.6 \%$ (Alfadhli et al., 2015). We aim to study the level of vitamin D in females with GDM.

This study attempted to identify relation between vitamin D deficiency in normal pregnant females and GDM subjects.

\section{Methodology:-}

Ethical approval for this study was obtained from the Unit of Biomedical Ethics and Research Committee at King Abdulaziz University, faculty of medicine in November 2015. Reference number is 360-15.

This cross sectional study was conducted at Obstetrics and Gynecology outpatient clinic and inpatient obstetrics ward at King Abdulaziz University hospital, Jeddah, Saudi Arabia. The study lasted for four months from January to April 2016. A written consent in the Arabic language was obtained on a form which was approved by the ethical committee from each volunteer following detailed explanation of the procedure and investigation. 92 subjects who fulfilled the inclusion criteria were enrolled in the study. Based on the American Diabetes Association (ADA) guidelines for the screening of Gestational diabetes mellitus (GDM), which is mostly used at the Obstetrics outpatient clinic at King Abdulaziz University hospital, subjects were divided into non-GDM and GDM groups. The non-GDM group included 60 subjects and the GDM group included 32 subjects.

The method used for diagnosing GDM had a two step approach. In the first step all pregnant women included in the study were screened for GDM after 24 weeks of gestation, by a one hour 50 grams Glucose Challenge Test (GCT) regardless of their fasting conditions. Second step, subjects with plasma glucose level measured one hour after the load with blood glucose $\geq 140 \mathrm{mg} / \mathrm{dl}(7.8 \mathrm{mmol} / \mathrm{L})$ proceed to $100 \mathrm{gm}$ Oral Glucose Tolerance Test (OGTT). $100 \mathrm{gm}$ OGTT was performed on another day. The patient was asked to fast for 8 hours then fasting blood was withdrawn 
then 100 gm oral glucose solution was given, after that blood was withdrawn at 3 sbsequent times at the interval of one hour each. GDM was diagnosed when two or more plasma levels met or exceeded the following values:

Fasting: $95 \mathrm{mg} / \mathrm{dl}(5.3 \mathrm{mmol} / \mathrm{L})$

One hour: $180 \mathrm{mg} / \mathrm{dl}(10 \mathrm{mmol} / \mathrm{L})$

Two hour: $155 \mathrm{mg} / \mathrm{dl}(8.6 \mathrm{mmol} / \mathrm{L})$

Three hour: $140 \mathrm{mg} / \mathrm{dl}(7.8 \mathrm{mmol} / \mathrm{L})$.

For subjects considered high risk for gestational diabetes, OGTT was carried out without GCT.

The data collected included personal and demographic information, anthropometric measurements, gravidity, parity, incidence of abortion, gestational week, calcium and vitamin D supplements, history of GDM, Family history of GDM and DM and medical and surgical history.

Blood samples were taken into tubes containing tripotassium ethylenediaminetetraacetic acid (EDTA) and each tube was centrifuged at $3000 \mathrm{rpm}$ for 5 minutes and the serum obtained was separated and stored then used at the time of analysis.

Vitamin D levels were determined using an automated direct competitive chemiluminescent immunoassay. Plasma glucose levels and HbA1c were determined at the Biochemistry lab using an automated analyzer.

Statistical Package for Social Sciences (SPSS) program version 20 was utilized for data entry and analysis. Frequency and percentage were used for description of categorical variables while mean and standard deviation were utilized to describe continuous variables \& median (quartile) was utilized to describe non- parametric variables. Chi-square test, independent t test, One way ANOVA, Pearson's correlation \& Mann-Whiteny U were adopted to check the relation and/or variance between variables. A p-value less than 0.05 was considered as statistically significant.

\section{Results:-}

During the period from January 2016 to April 2016, 92 pregnant women from total population of 400 screened subjects met the inclusion criteria. 32 of the 92 subjects had gestational diabetes (GDM) and 60 subjects had normal glucose profile (Non GDM). 9 subjects out of the 92 had normal Vitamin D. Out of the 9 normal vitamin D group 3 had GDM and 6 subjects did not have GDM, The mean of vitamin D level for GDM group was $24.1 \pm 13.9$ and for non GDM group was $27.3 \pm 12.8$ with no statistical significance.

The 92 subjects were divided into the following six groups depending on their vitamin D status. Vitamin D normal $(25(\mathrm{OH})$ vit D $50 \mathrm{nmol} / \mathrm{L})$, insufficient $(25(\mathrm{OH})$ vitD $25-50 \mathrm{nmol} / \mathrm{L})$ and deficient $(25(\mathrm{OH})$ vit $\mathrm{D}<25 \mathrm{nmol} / \mathrm{L}) \mathrm{groups}$ (Hospital, 2016)

There was no statistical difference between the mean of the non GDM and GDM group concerning vitamin D levels (Table 1).

All the 92 subjects were distributed into four quartiles depending on vitamin D level. They were arranged from lowest value to highest value of vitamin D. $30.4 \%$ of quartile 4 that is 6 females had GDM while $47.8 \%$ of quartile 1 that is 12 females had GDM with no statistical significance. No statistical significance was found between quartiles $1 \& 4$ regarding all other variables. (Table 2A\&2B)

The Age, BMI, Gestation age, Gravidity, and Parity were considered for comparison in the above mentioned six groups. In the group with normal Vitamin D there was no statistical difference between the GDM and non GDM groups as regards the previously mentioned parameters. In the insufficient group there was a statistical difference between non GDM and the GDM in age, BMI, gravidity and parity. The risk of GDM being higher with higher age, BMI, gravidity and parity. In the vitamin D deficient group, higher age showed higher risk of GDM (Table 3).

When compared for previous GDM, family history of GDM, family history of DM, nationality and BMI, obesity significantly increased the risk of GDM among insufficient vitamin D status. Rest of the comparisons showed no significant difference (Table 4). 
There was no significant difference between GDM and non GDM subjects regarding positive family history of GDM. In the GDM group 18.8\% had previous GDM while in non GDM group $6.7 \%$ had previous GDM. Family history of DM was reported by $71.9 \%$ of GDM group and 55\% of non GDM group.71.0\% of the GDM group were obese. In the non GDM group $38.6 \%$ were obese (Table 4).

The mean age in the GDM group was $31.9 \pm 4.8$ and in the non GDM was $26.9 \pm 5.6$ with a statistical significance $(\mathrm{p}=0.001)$. BMI was another parameter where statistical difference was found among the GDM and non GDM group. Mean score of BMI in GDM group was $32.3 \pm 5.8$ and non GDM was $28.3 \pm 5.5$ ( $\mathrm{p}=0.002$ ). No statistically significant difference was found among the two groups as per the following parameters: Gestational Age (GA), gravity \& parity (Table 5).

The result of comparison between GDM \& non GDM groups according to glucose lab investigation showed a statistical difference for GCT, the mean for GDM \& non GDM groups were 9.7 $\pm 1.4,7.1 \pm 1.5$ respectively $(\mathrm{p}=0.001)$. For HbA1C, the mean for GDM \& non GDM groups were 5.7 $\pm 0.7,5.3 \pm 0.8$ respectively $(\mathrm{p}=0.02)$. The results showed statistical difference between GDM \& non GDM groups for all remaining variables (GTTF, GTT1, GTT2, GTT3) ( $\mathrm{p}=0.001, \mathrm{p}=0.001, \mathrm{p}=0.001, \mathrm{p}=0.001)$ respectively (Table 6A).

There was statistical difference between the means of the six groups concerning GCT $(8.8 \pm 0.9,10.1 \pm 1.4,9.7 \pm 1.4$ , $6.7 \pm 1.2,7.0 \pm 1.4,7.1 \pm 1.6$ ) respectively. All glucose investigations showed statistical difference (GTTF, GTT1, GTT2, GTT3) $\mathrm{p}=0.02, \mathrm{p}<0.0001, \mathrm{p}<0.0001, \mathrm{p}<0.0001$ respectively, while only HbA1C showed no statistical difference (Table 6B).

Correlation between vitamin D \& several variables among the GDM \& non GDM groups was seen. There was a negative correlation between vitamin D and BMI with no statistical difference. Also there was a negative correlation in all glucose lab results with vitamin D (Table 7) \&( figures 4-16).

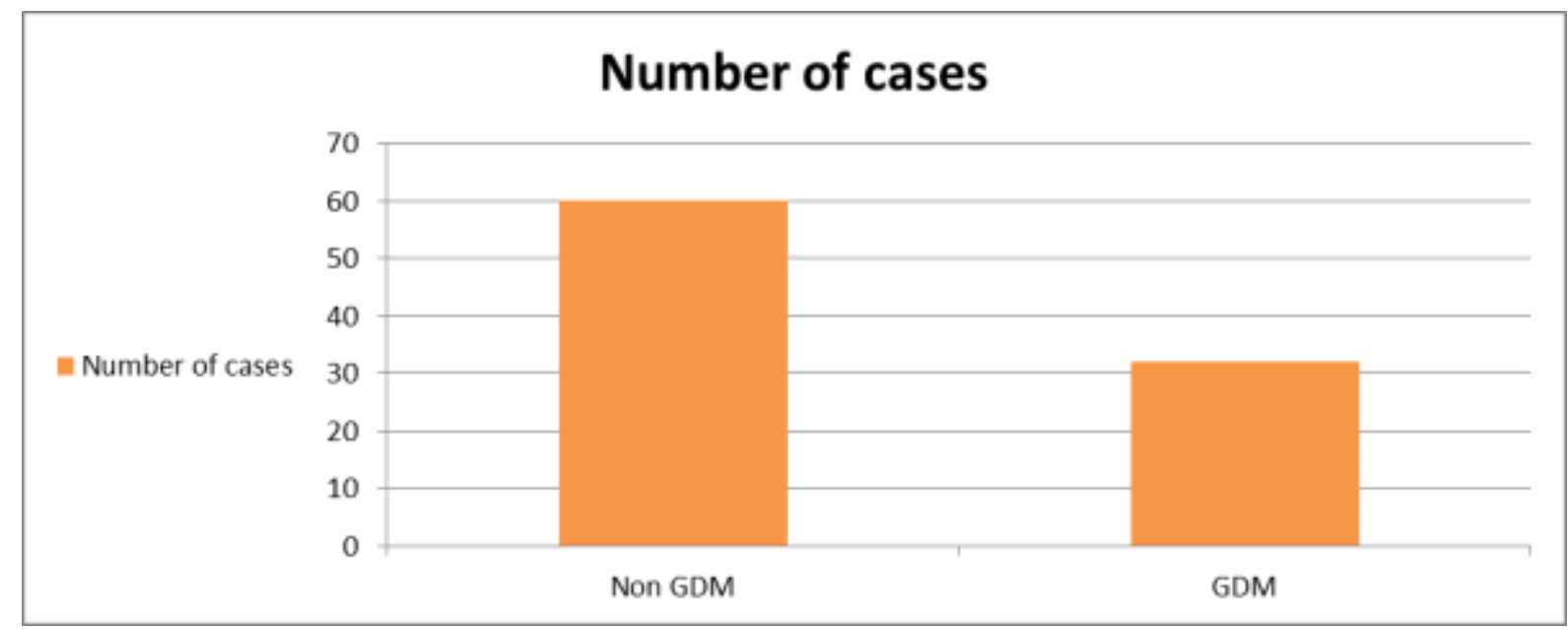

Graph 1:- 32 of the 92 subjects had gestational diabetes (GDM) and 60 subjects had normal glucose profile (Non GDM) 


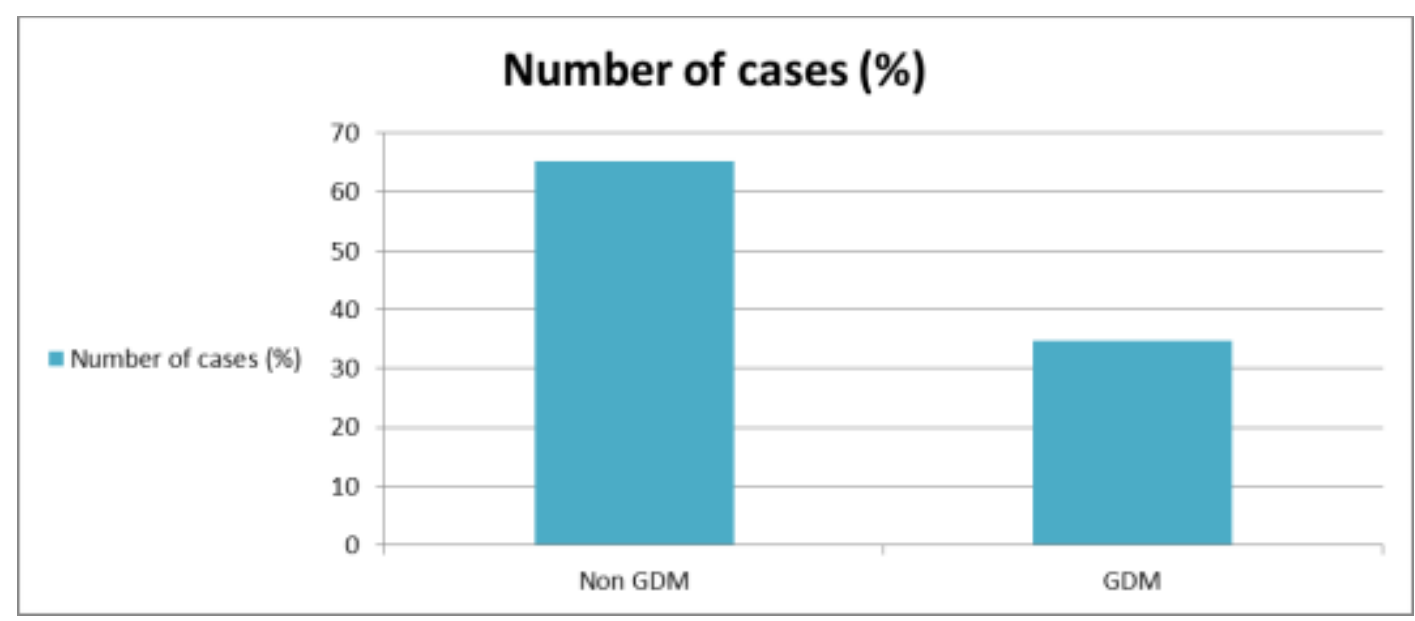

Graph 2:- GDM and Non GDM cases compared as \%.

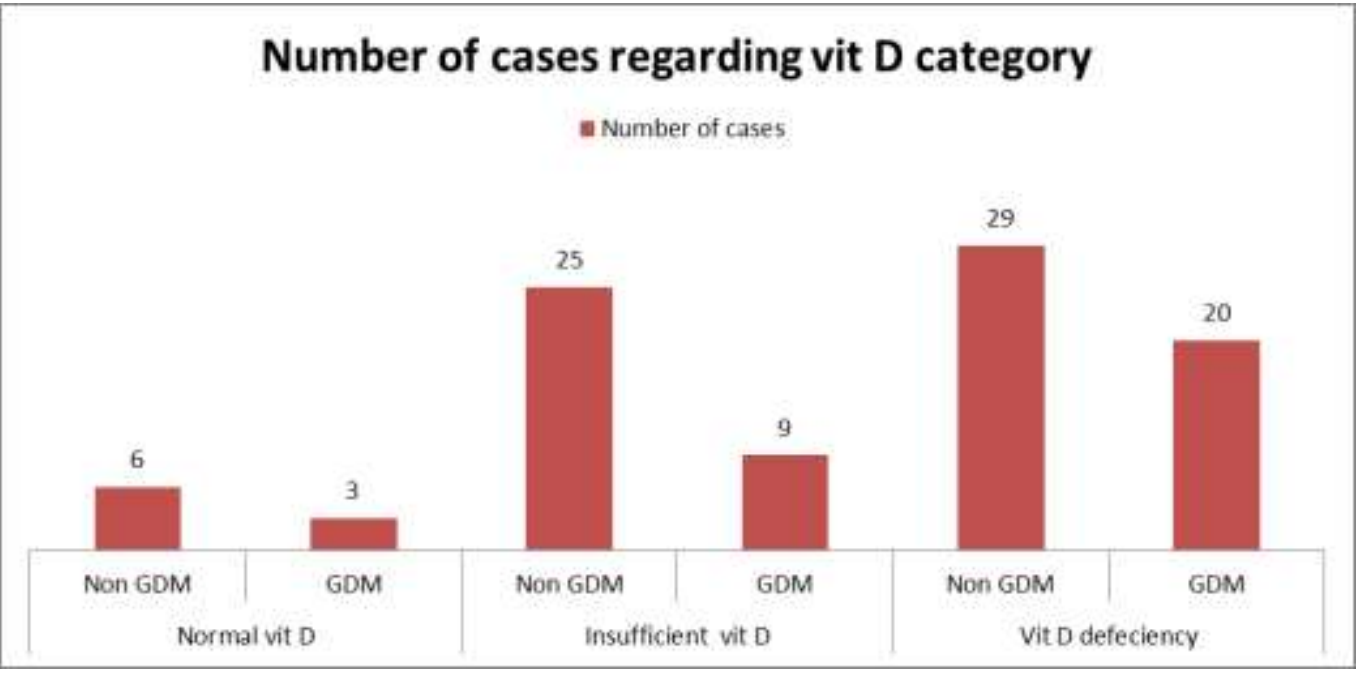

Graph 3:- Number of Non GDM and GDM cases according to vitamin D level categorized as Normal, In sufficient and Deficient categories.

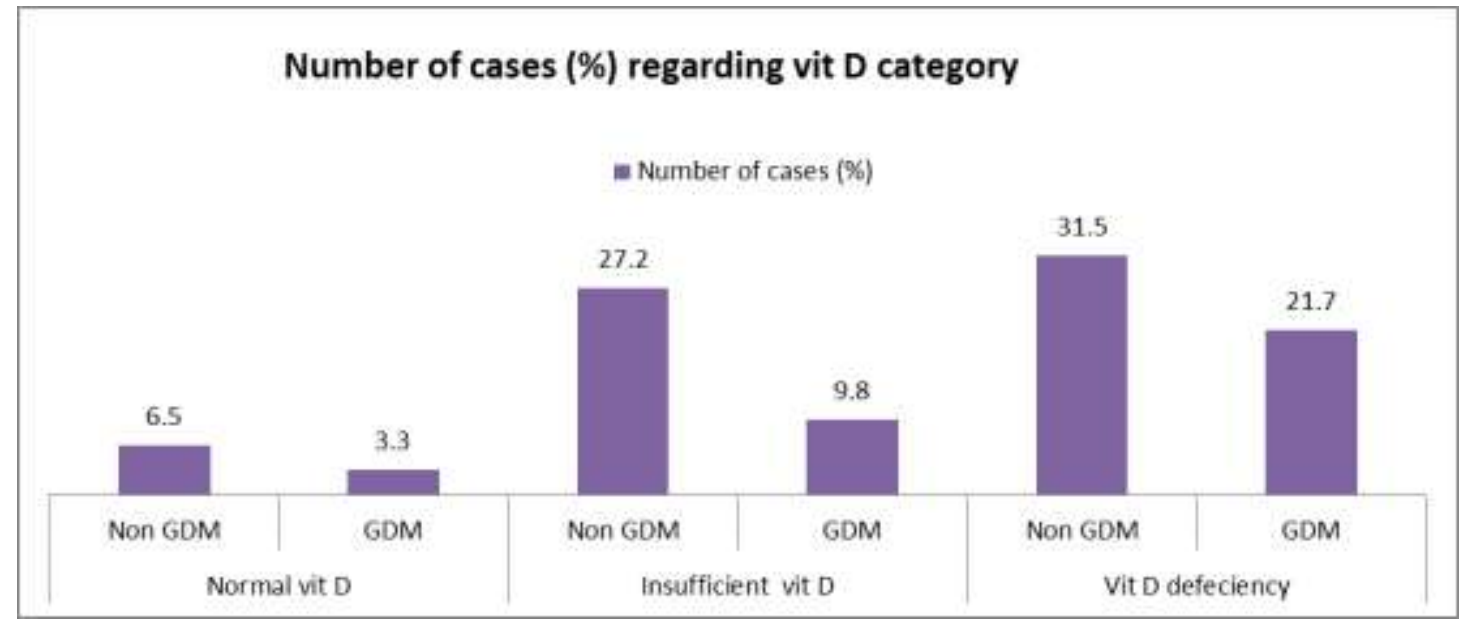

Graph 4:- Number of cases (\%) regarding vit D category. 


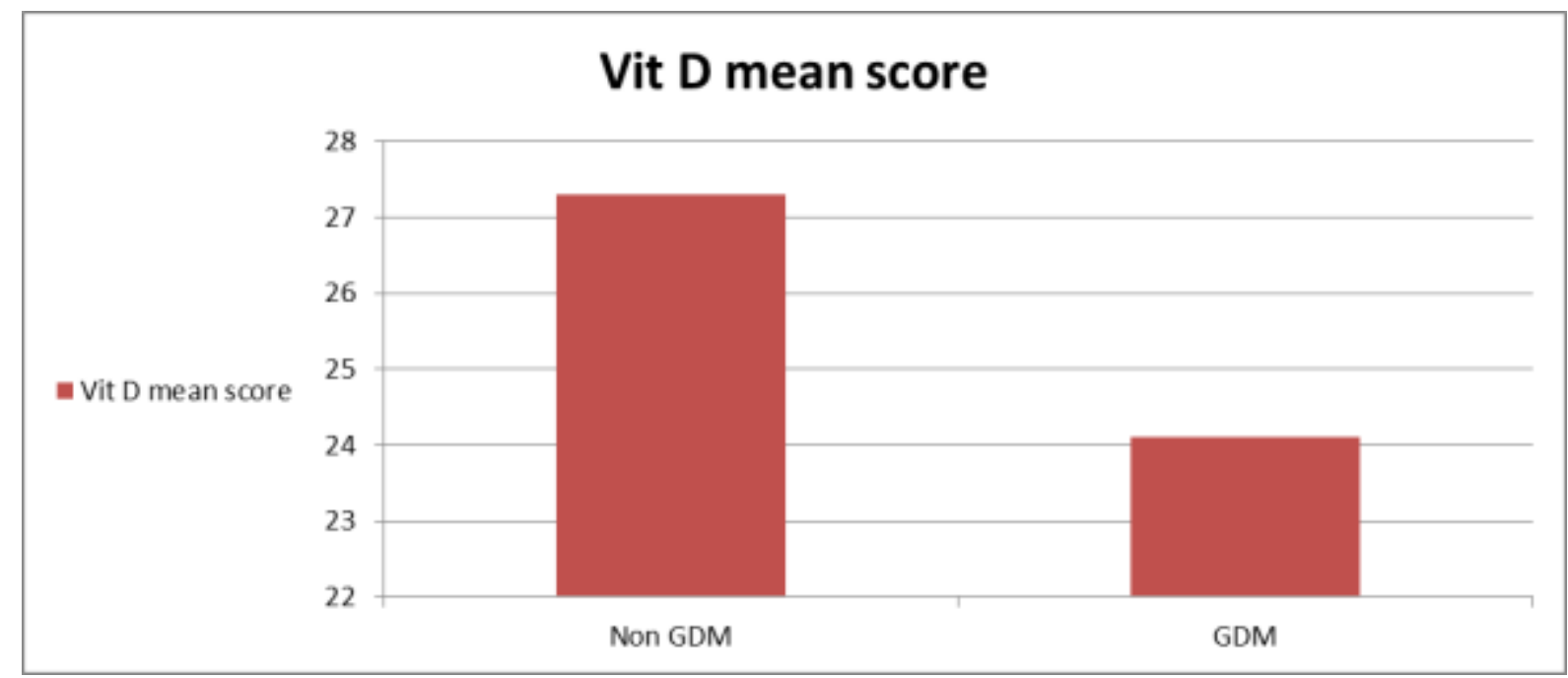

Graph 5:- Vitamin D mean score.

Table (1):- Comparison between non GDM \& GDM groups according to vitamin D level

\begin{tabular}{|c|l|l|c|}
\hline Variables & $\begin{array}{l}\text { Non GDM group } \\
\mathbf{N = 6 0}\end{array}$ & $\begin{array}{l}\text { GDM group } \\
\mathbf{N = 3 2}\end{array}$ & P value \\
\hline Vitamin D & $27.3 \pm 12.8$ & $24.1 \pm 13.9$ & $\mathbf{0 . 3}$ \\
\hline $\mathbf{m m o l} / \mathbf{L}$ & & & \\
\hline
\end{tabular}

Data are presented as mean +/- SD. (minimum - maximum).

Significance between non GDM \& GDM groups was determined using independent $t$ test.

*Statistical significance at 0.05 or less.

Table (2A):- Comparison between $1^{\text {st }} \& 4^{\text {th }}$ quartiles according to vitamin D levels:

\begin{tabular}{|c|c|c|c|c|c|}
\hline \multirow{2}{*}{\multicolumn{3}{|c|}{ Variables }} & \multicolumn{2}{|l|}{ Groups } & P value \\
\hline & & & & & \\
\hline \multirow{2}{*}{\multicolumn{2}{|c|}{ Cases }} & GDM & $\begin{array}{l}1^{\text {st }} \text { quartile } \\
\mathrm{N}=23 \\
12(52.2 \%)\end{array}$ & $6 \quad(29.2 \%)$ & \multirow[t]{2}{*}{0.1} \\
\hline & & GDM Non & $11(47.8 \%)$ & $17(70.8 \%)$ & \\
\hline \multirow{2}{*}{\multicolumn{2}{|c|}{ Prev. }} & No & $21(91.3 \%)$ & $21(91.7 \%)$ & \multirow[t]{2}{*}{0.7} \\
\hline & & Yes & $\begin{array}{ll}2 & (8.7 \%)\end{array}$ & $\begin{array}{ll}2 & (8.3 \%)\end{array}$ & \\
\hline \multirow{4}{*}{ M } & \multirow[t]{2}{*}{ FH.GD } & No & $17(73.9 \%)$ & $18(75.0 \%)$ & \multirow[t]{2}{*}{0.6} \\
\hline & & Yes & $\begin{array}{ll}6 & (26.1 \%)\end{array}$ & $\begin{array}{ll}5 & (25.0 \%)\end{array}$ & \\
\hline & \multirow[t]{2}{*}{ FH.DM } & No & $\begin{array}{ll}8 & (34.8 \%) \\
\end{array}$ & $9 \quad(37.5 \%)$ & \multirow[t]{2}{*}{0.6} \\
\hline & & Yes & $15(65.2 \%)$ & $14(62.5 \%)$ & \\
\hline
\end{tabular}

Data are presented as number \& percentage (\%)

Significance between non GDM \& GDM groups was determined using Chi-square test

*Statistical significance at 0.05

Table (2B):- Comparison between $1^{\text {st }} \& 4^{\text {th }}$ quartiles according to vitamin D levels:

\begin{tabular}{|c|c|c|c|}
\hline \multirow[t]{2}{*}{ Variables } & \multicolumn{2}{|l|}{ Groups } & \multirow[t]{2}{*}{$P$ value } \\
\hline & $\begin{array}{l}1^{\text {st }} \text { quartile } \\
\mathbf{N}=23\end{array}$ & $\begin{array}{l}4^{\text {th }} \text { quartile } \\
\mathrm{N}=23\end{array}$ & \\
\hline Age & $27.1 \pm 6.3$ & $26.6 \pm 5.3$ & 0.2 \\
\hline BMI & $30.6 \pm 7.9$ & $30.5 \pm 4.8$ & 0.9 \\
\hline GA & $32.1 \pm 4.6$ & $31.2 \pm 3.9$ & 0.5 \\
\hline Gravidity & $3.0 \pm 2.3$ & $3.0 \pm 1.7$ & 0.6 \\
\hline Vitamin D & $12.0 \pm 1.7$ & $45.2 \pm 8.1$ & $0.0001 * *$ \\
\hline HbA1C & $5.7 \pm 1.0$ & $5.3 \pm 0.5$ & 0.1 \\
\hline
\end{tabular}




\begin{tabular}{|l|l|l|l|}
\hline GCT & $\mathbf{8 . 1} \pm 2.5$ & $7.9 \pm 1.9$ & 0.8 \\
\hline GTTF & $\mathbf{5 . 3} \pm 1.1$ & $\mathbf{5 . 0 \pm 0 . 6}$ & $\mathbf{0 . 4}$ \\
\hline GTT1 & $\mathbf{1 1 . 0} \pm 2.7$ & $\mathbf{9 . 7} \pm 1.8$ & $\mathbf{0 . 1}$ \\
\hline GTT2 & $\mathbf{9 . 5} \pm 2.9$ & $\mathbf{7 . 7 \pm 2 . 3}$ & $\mathbf{0 . 0 9}$ \\
\hline GTT3 & $\mathbf{7 . 3} \pm 2.4$ & $\mathbf{6 . 9} \pm 1.6$ & $\mathbf{0 . 6}$ \\
\hline
\end{tabular}

Data are presented as mean +/- SD. (minimum - maximum)

Significance between non GDM \& GDM groups was determined using t-test

*Statistical significance at 0.05

Table (3):- Comparison between non GDM \& GDM groups according to personal \& medical history \& vitamin D status:

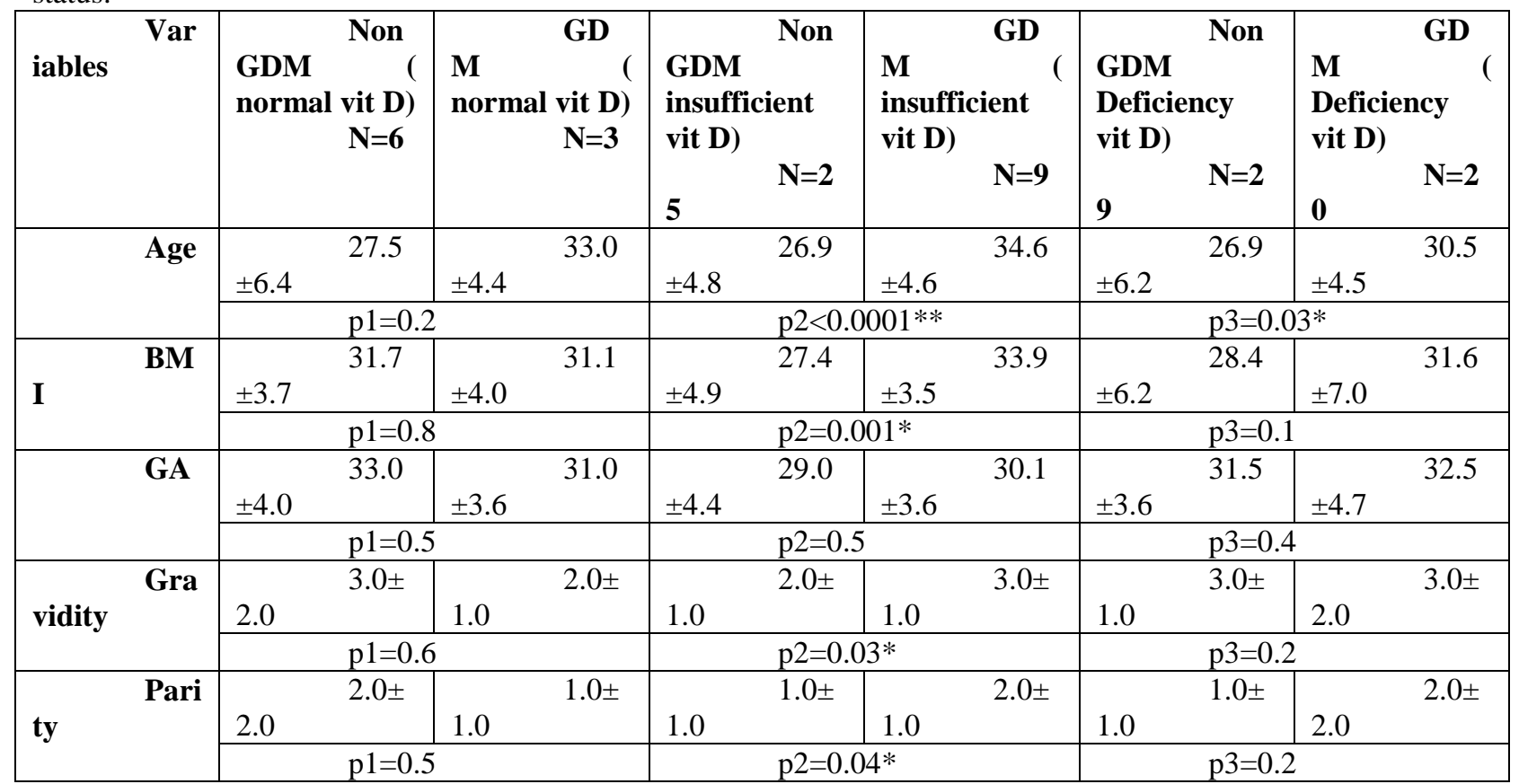

Data are presented as mean +/- SD. (minimum - maximum).

Significance was made using independent $t$ test.

p1 significant difference between non GDM \& GDM groups with normal vit D level.

p2 significant difference between non GDM \& GDM groups with insufficient vit D level .

p3 significant difference between non GDM \& GDM groups with deficiency in vit D level

*Statistical significance at 0.05 .

**Extremely significant at 0.0001 .

GDM: gestational diabetes mellitus.

BMI: body mass index.

GA: gestational age.

Table (4):- Percentage variation between non GDM \& GDM groups according to family history of GDM \& DM, BMI index \& vitamin D status:

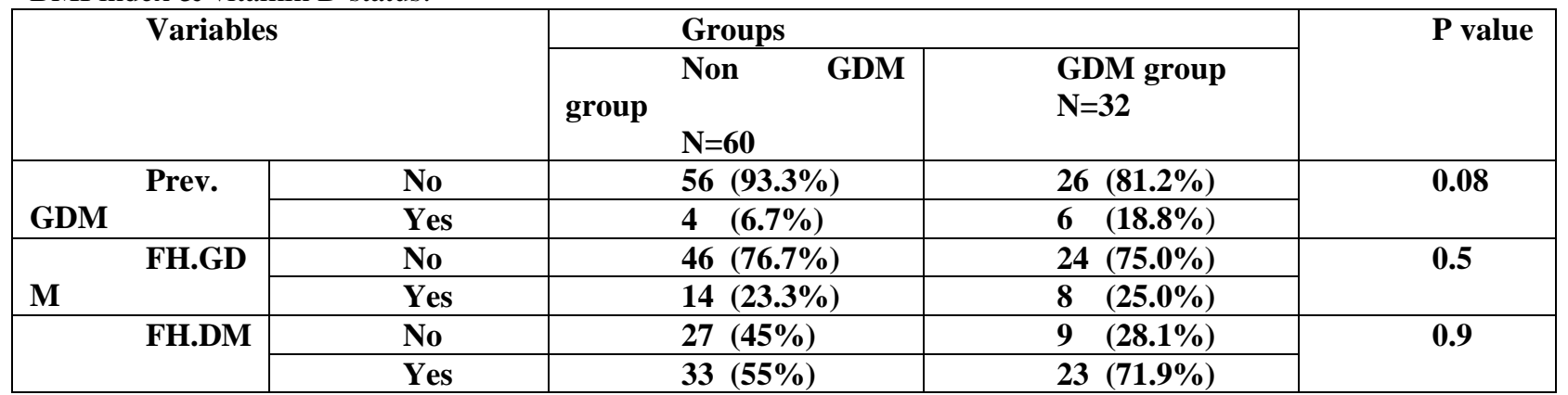




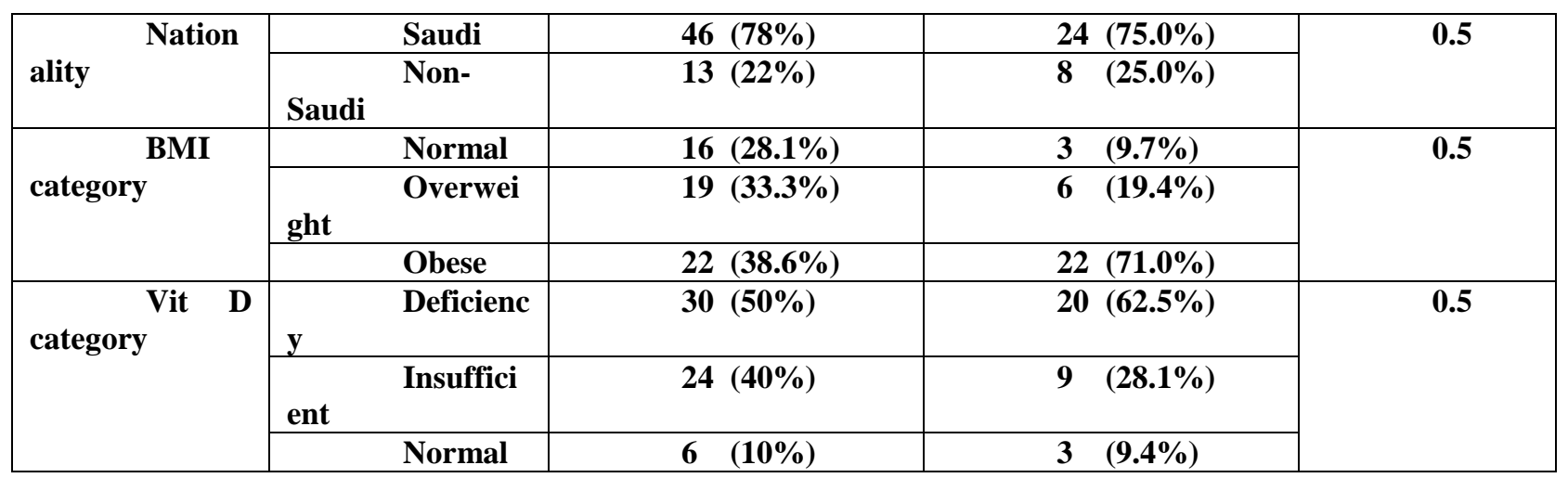

Data are presented as number \& percentage (\%).

Significance between non GDM \& GDM groups was determined using Chi-square test.

*Statistical significance at the 0.05 level.

BMI: Body Mass Index / GA : Gestational age

Table (5):- Comparison between non GDM \& GDM groups according to personal \& medical history:

\begin{tabular}{|l|l|l|l|}
\hline Variables & $\begin{array}{l}\text { Non GDM group } \\
\mathbf{N = 6 0}\end{array}$ & $\begin{array}{l}\text { GDM group } \\
\mathbf{N = 3 2}\end{array}$ & P value \\
\hline Age & $26.9 \pm 5.6$ & $31.9 \pm 4.8$ & $0.001^{*}$ \\
\hline BMI & $28.3 \pm 5.5$ & $32.3 \pm 5.8$ & $0.002^{*}$ \\
\hline GA in weeks & $30.6 \pm 4.2$ & $31.7 \pm 4.3$ & 0.2 \\
\hline Gravidity & $3.0 \pm 1.0$ & $3.0 \pm 2.0$ & 0.08 \\
\hline Parity & $1.0 \pm 1.0$ & $2.0 \pm 2.0$ & 0.06 \\
\hline
\end{tabular}

Data are presented as mean +/- SD. (minimum - maximum).

Significance between non GDM \& GDM groups was determined using independent $\mathrm{t}$ test.

*Statistical significance at 0.05 .

BMI: body mass index.

GA: gestational age.

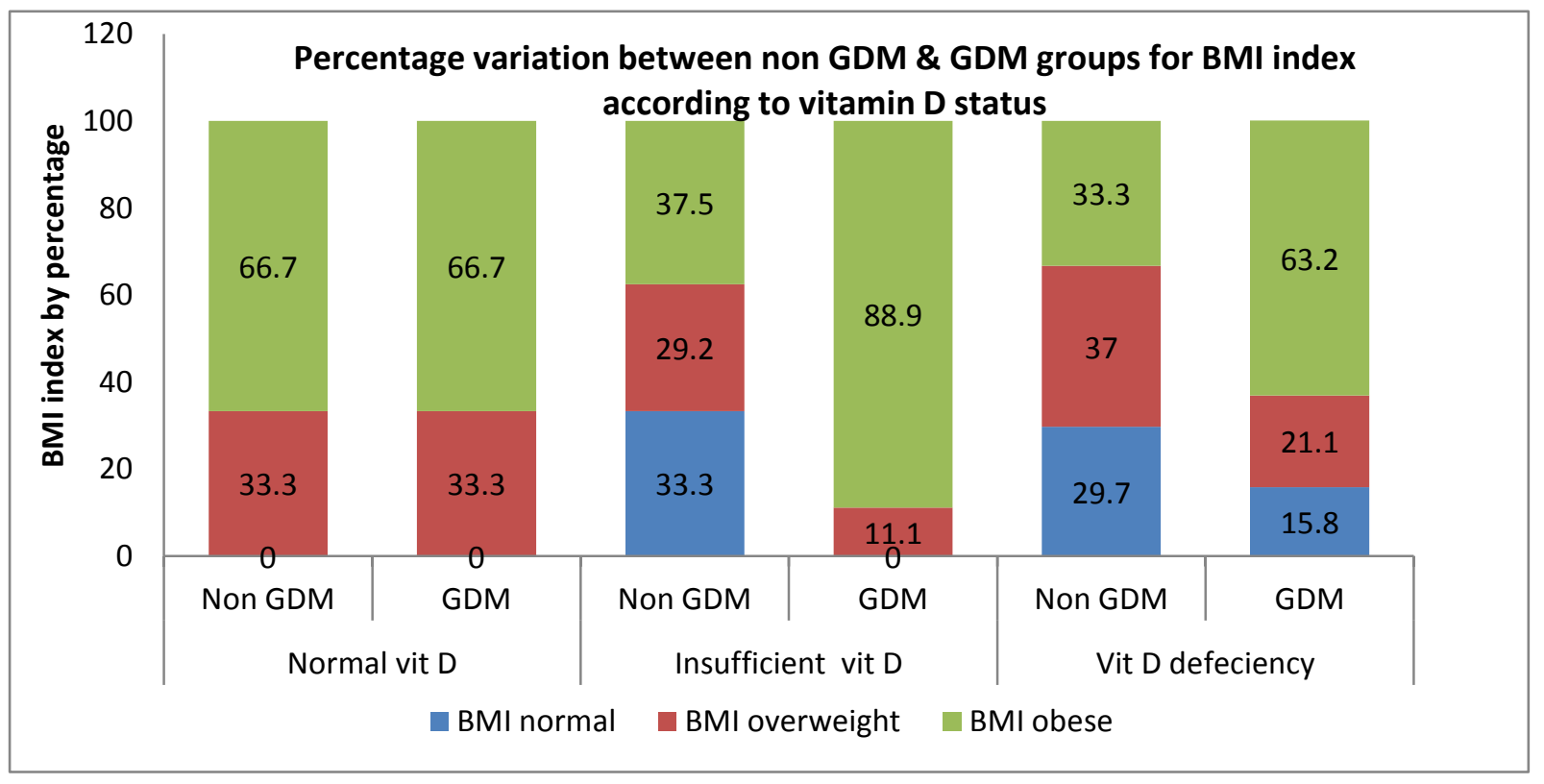

Figure (1):- Percentage variation between non GDM \& GDM groups for BMI index according to vitamin D status 
Table (6A):- Comparison between non GDM \& GDM groups according to HbA1C, GCT \& GTT:

\begin{tabular}{|c|c|c|c|}
\hline Variables & $\begin{array}{l}\text { Non GDM group } \\
\mathbf{N}=\mathbf{6 0}\end{array}$ & $\begin{array}{l}\text { GDM group } \\
\mathrm{N}=32\end{array}$ & p value \\
\hline HbA1C & $5.3 \pm 0.8$ & $5.7 \pm 0.7$ & $0.02 *$ \\
\hline 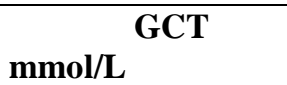 & $7.1 \pm 1.5$ & $9.7 \pm 1.4$ & $0.001 *$ \\
\hline $\mathrm{mmol} / \mathrm{L}^{\text {GTTF }}$ & $4.7 \pm 0.4$ & $5.4 \pm 0.8$ & $0.001 *$ \\
\hline $\mathrm{mmol} / \mathrm{L}^{\text {GTT1 }}$ & $8.6 \pm 1.7$ & $11.5 \pm 1.8$ & $0.001^{*}$ \\
\hline $\mathrm{mmol} / \mathrm{L}^{\text {GTT2 }}$ & $6.9 \pm 1.3$ & $10.4 \pm 2.2$ & $0.001 *$ \\
\hline $\mathrm{mmol} / \mathrm{L}^{\text {GTT3 }}$ & $6.0 \pm 1.1$ & $8.1 \pm 1.6$ & $0.001 *$ \\
\hline
\end{tabular}

Data are presented as mean +/- SD. (minimum - maximum)

Significance between non GDM \& GDM groups was determined using independent $t$ test

*Statistical significance at 0.05 .

GCT : Glucose challenge test /GTTF : Glucose tolerance test fasting / GTT1 : Glucose tolerance test after 1 hour / GTT2 : Glucose tolerance test after 2 hours / GTT3 : Glucose tolerance test after 3 hour

Table (6B):- Comparison between non GDM \& GDM groups according to vitamin D status:

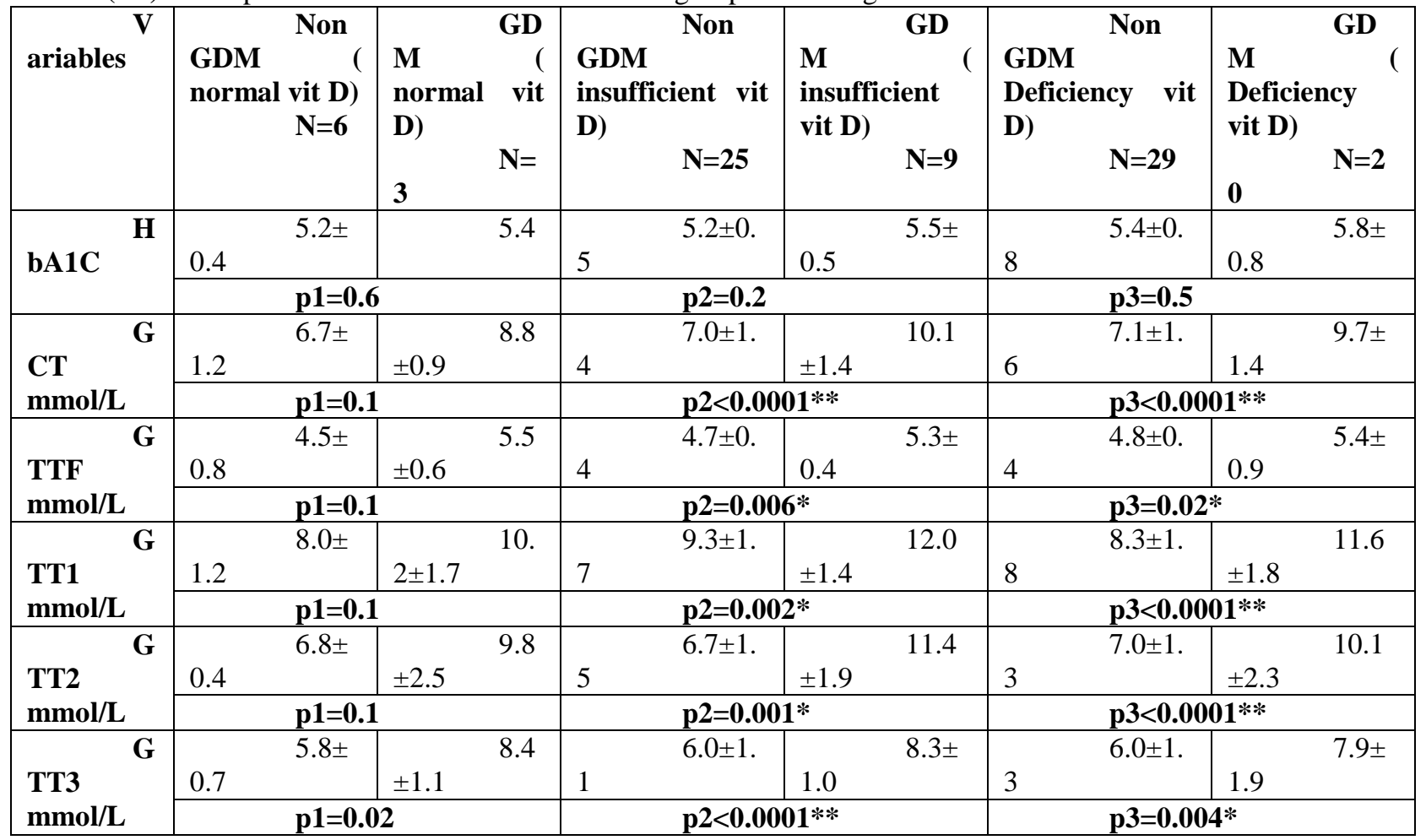

Data are presented as mean $+/$ - SD. (minimum - maximum)

Significant was made using independent $t$ test.

p1 significant difference between non GDM \& GDM groups with normal vit D level.

p2 significant difference between non GDM \& GDM groups with insufficient vit D level .

p3 significant difference between non GDM \& GDM groups with deficiency in vit D level

*Statistical significance at 0.05 .

**Extremely statistical significance at 0.0001 


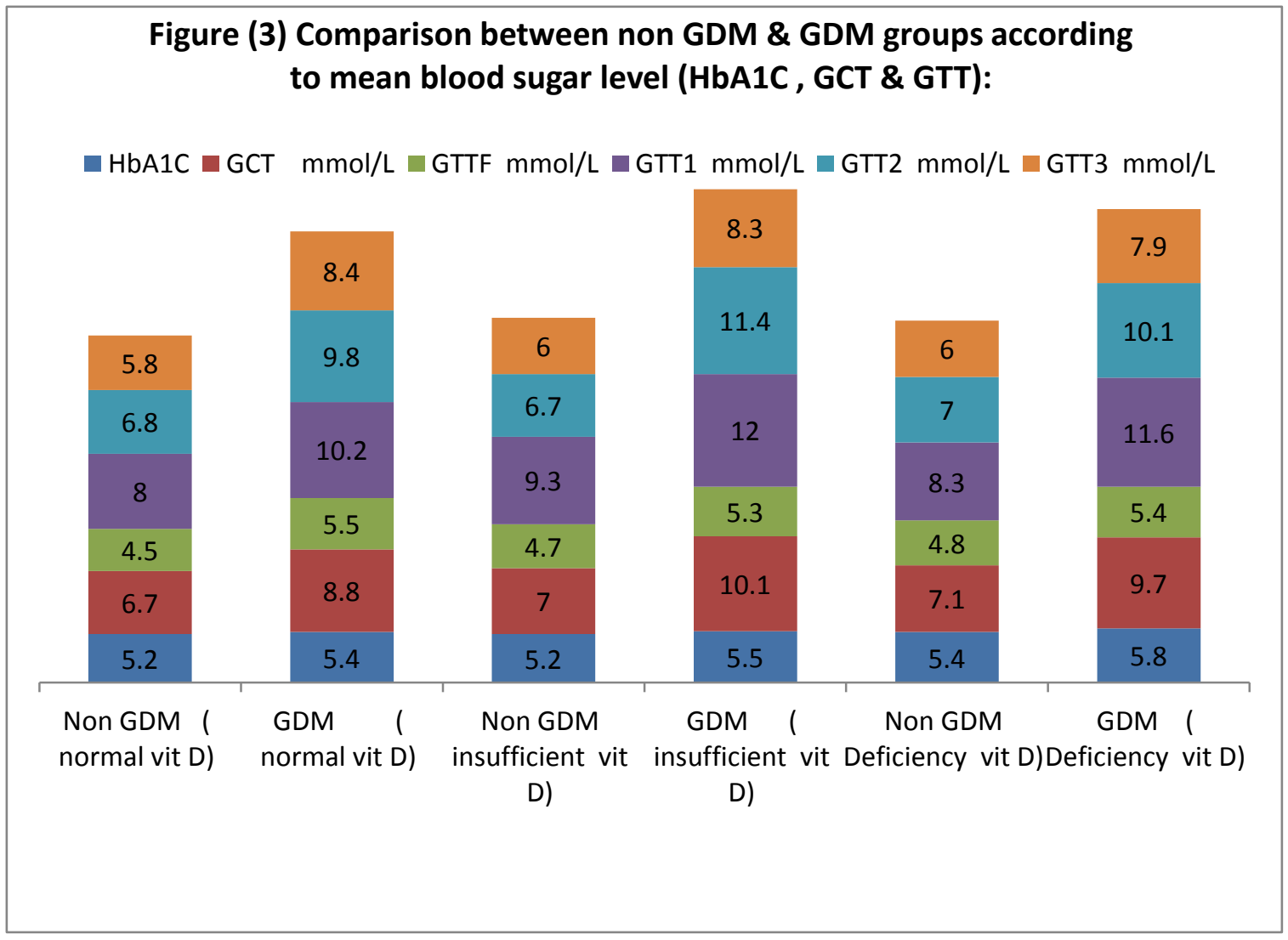

Figure (3):- Comparison between non GDM \& GDM groups according to mean blood sugar level (HbA1C, GCT \& GTT):

Table (7):- the correlation between vitamin D and other variables among non GDM \& GDM groups:

\begin{tabular}{|c|c|}
\hline Vitamin D correlation coefficient ( $r$ ) & $\mathrm{N}=92$ \\
\hline Age & $\begin{array}{l}r=0.1 \\
p=0.2\end{array}$ \\
\hline BMI & $\begin{array}{l}r=-0.7 \\
p=0.7\end{array}$ \\
\hline GA & $\begin{array}{l}r=-0.1 \\
p=0.2\end{array}$ \\
\hline Gr & $\begin{array}{l}r=-0.03 \\
p=0.7\end{array}$ \\
\hline Pr & $\begin{array}{l}r=-0.005 \\
p=0.9\end{array}$ \\
\hline Abortion & $\begin{array}{l}r=-0.1 \\
p=0.3\end{array}$ \\
\hline MPV & $\begin{array}{l}r=-0.3 \\
p-0.7\end{array}$ \\
\hline HbA1C & $\begin{array}{l}r=-0.1 \\
p=0.4\end{array}$ \\
\hline GCT $\mathrm{mmol} / \mathrm{L}$ & $\begin{array}{l}r=-0.07 \\
p=0.5\end{array}$ \\
\hline GTTF $\mathrm{mmol} / \mathrm{L}$ & $\begin{array}{l}r=-0.05 \\
p=0.7\end{array}$ \\
\hline GTT1 $\mathrm{mmol} / \mathrm{L}$ & $\begin{array}{l}r=-0.1 \\
p=0.3\end{array}$ \\
\hline GTT2 $\mathrm{mmol} / \mathrm{L}$ & $r=-0.2$ \\
\hline
\end{tabular}




\begin{tabular}{|l|l|}
\hline & $p=0.2$ \\
\hline GTT3 $\mathrm{mmol} / \mathrm{L}$ & $\mathrm{r}=-\mathbf{0 . 0 6}$ \\
& $\mathrm{p}=0.6$ \\
\hline
\end{tabular}

Correlation was done by using Person's correlation test.

* Statistical significance at 0.05 or less.

Figure (4):- Correlation between vitamin D \& age :

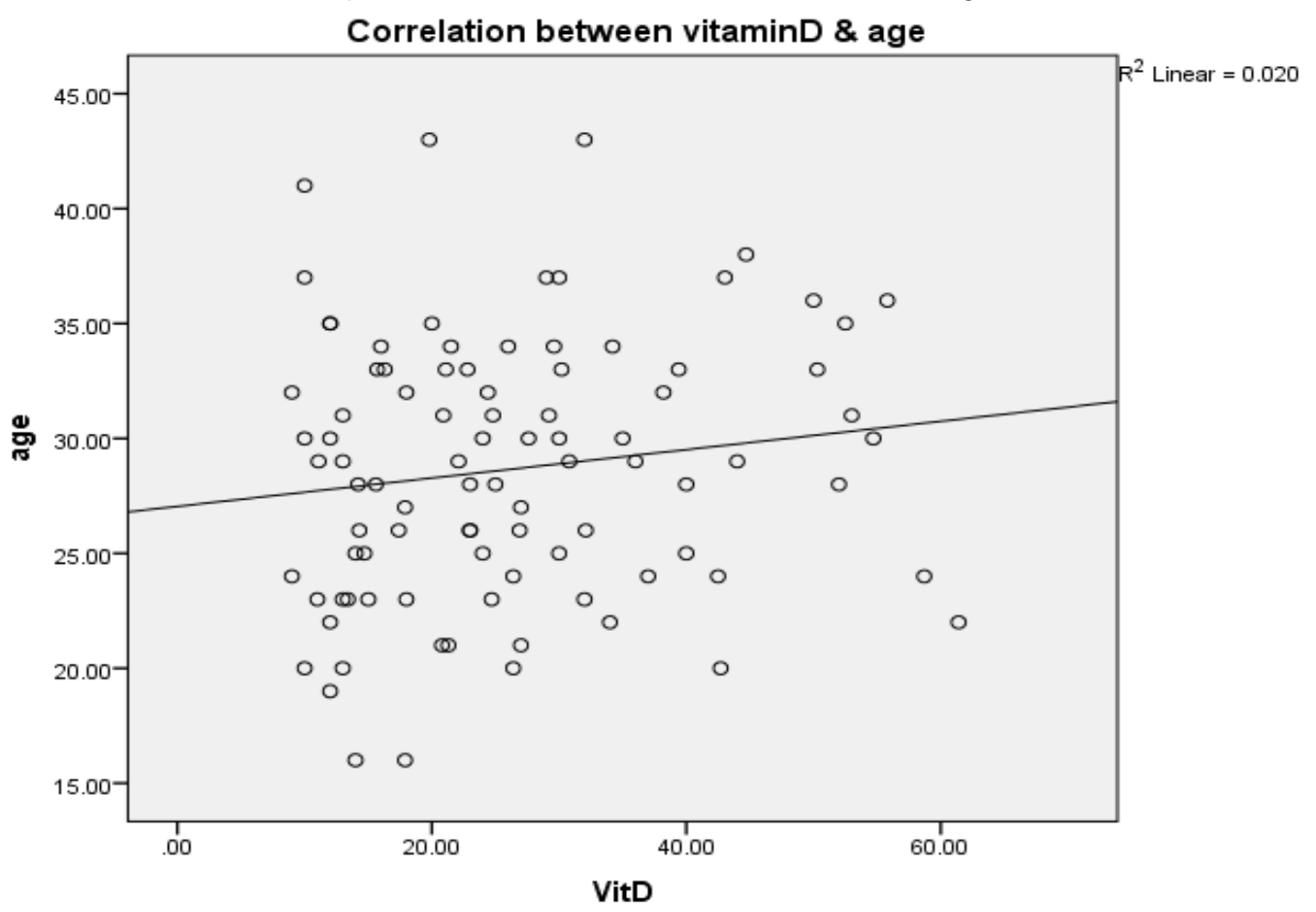

Figure (5):- Correlation between vitamin D \& BMI :

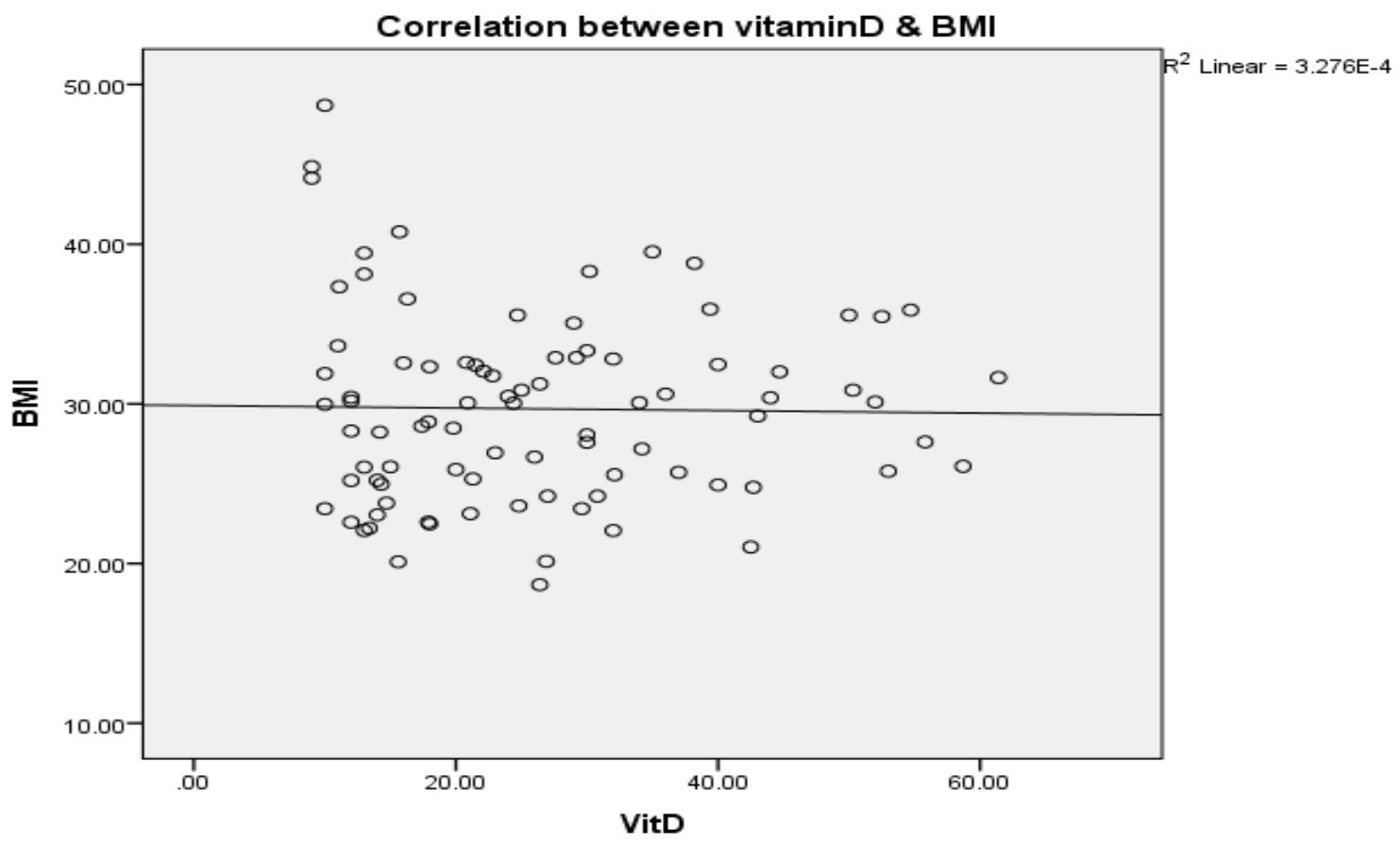


Figure (6):- Correlation between vitamin D \& GA

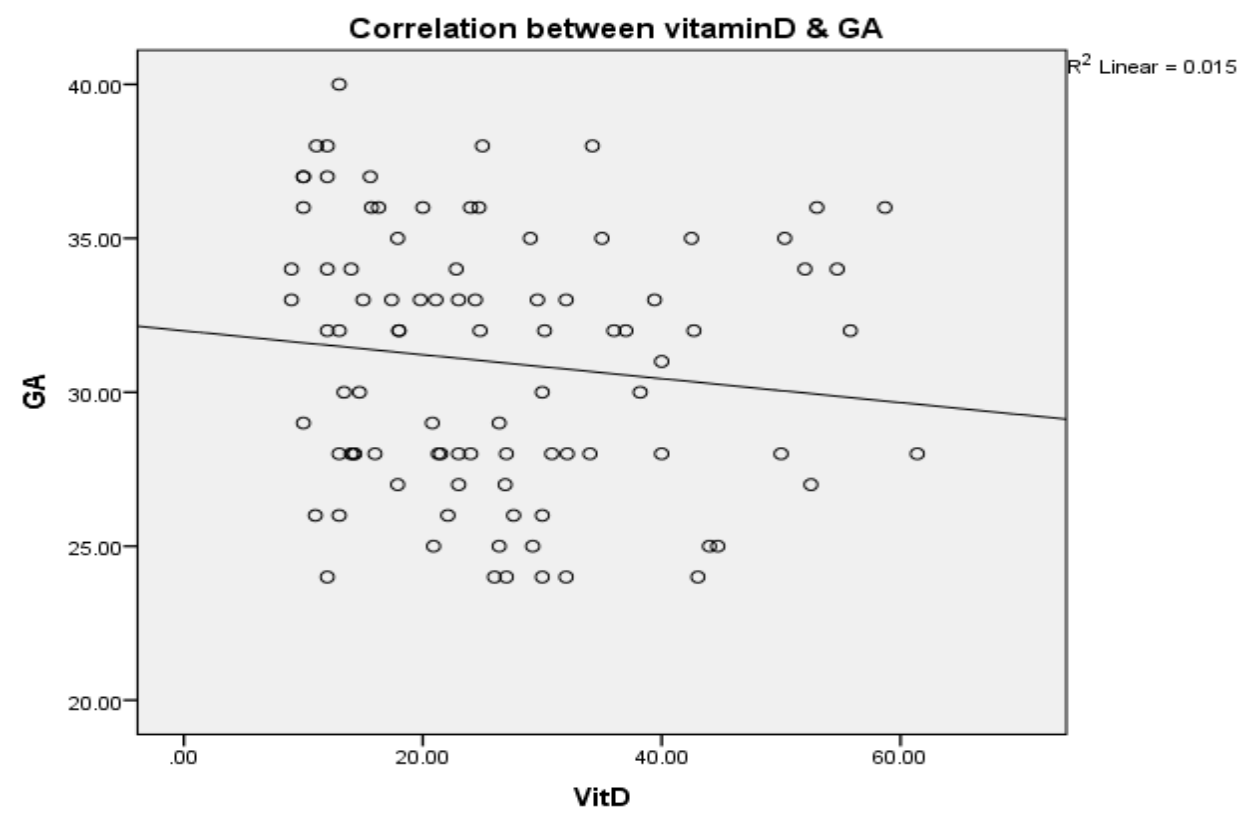

Figure (7):- Correlation between vitamin D \& gravidity:

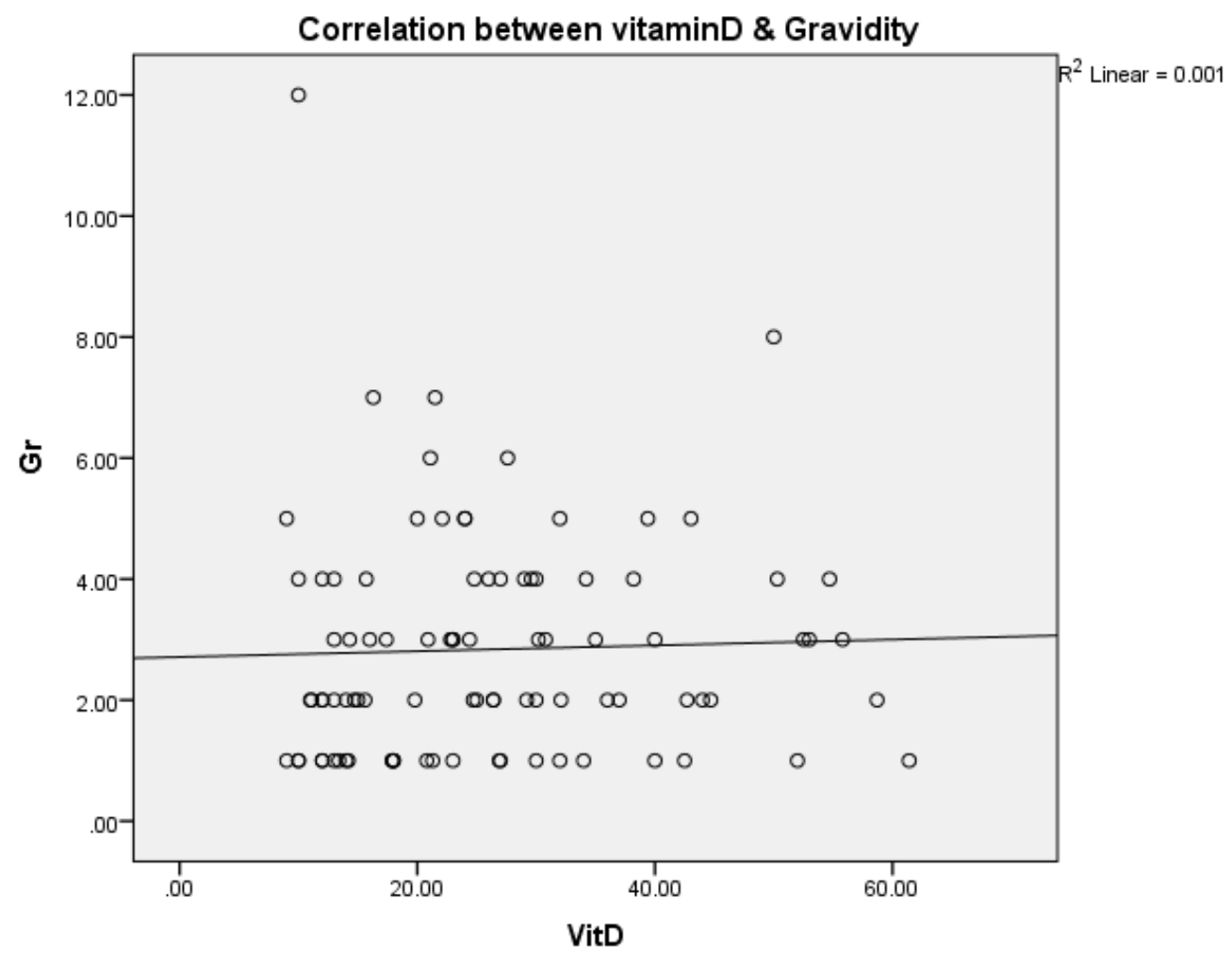


Figure (8):- Correlation between vitamin D \& parity:

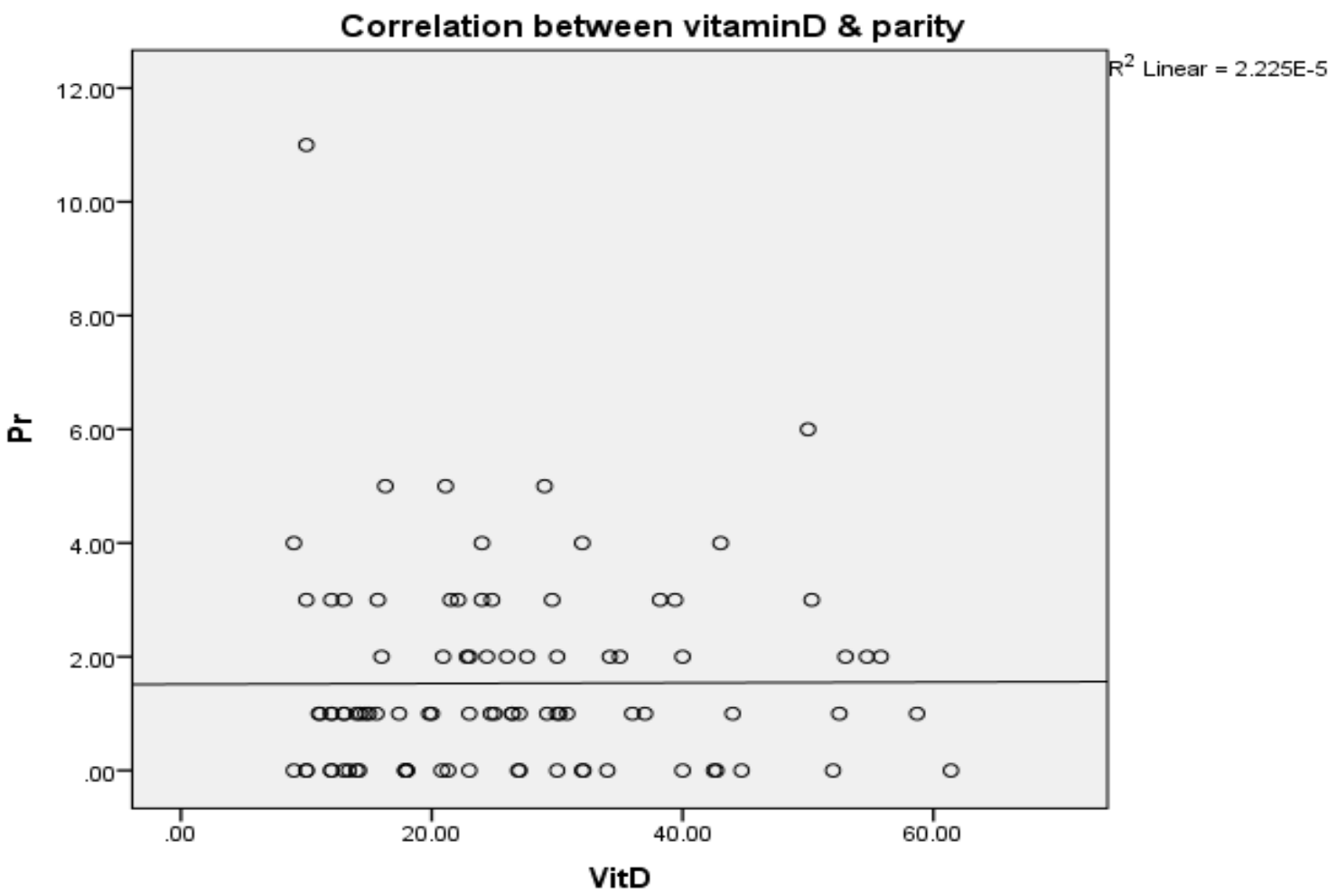

Figure (9):- Correlation between vitamin D \& abortion :

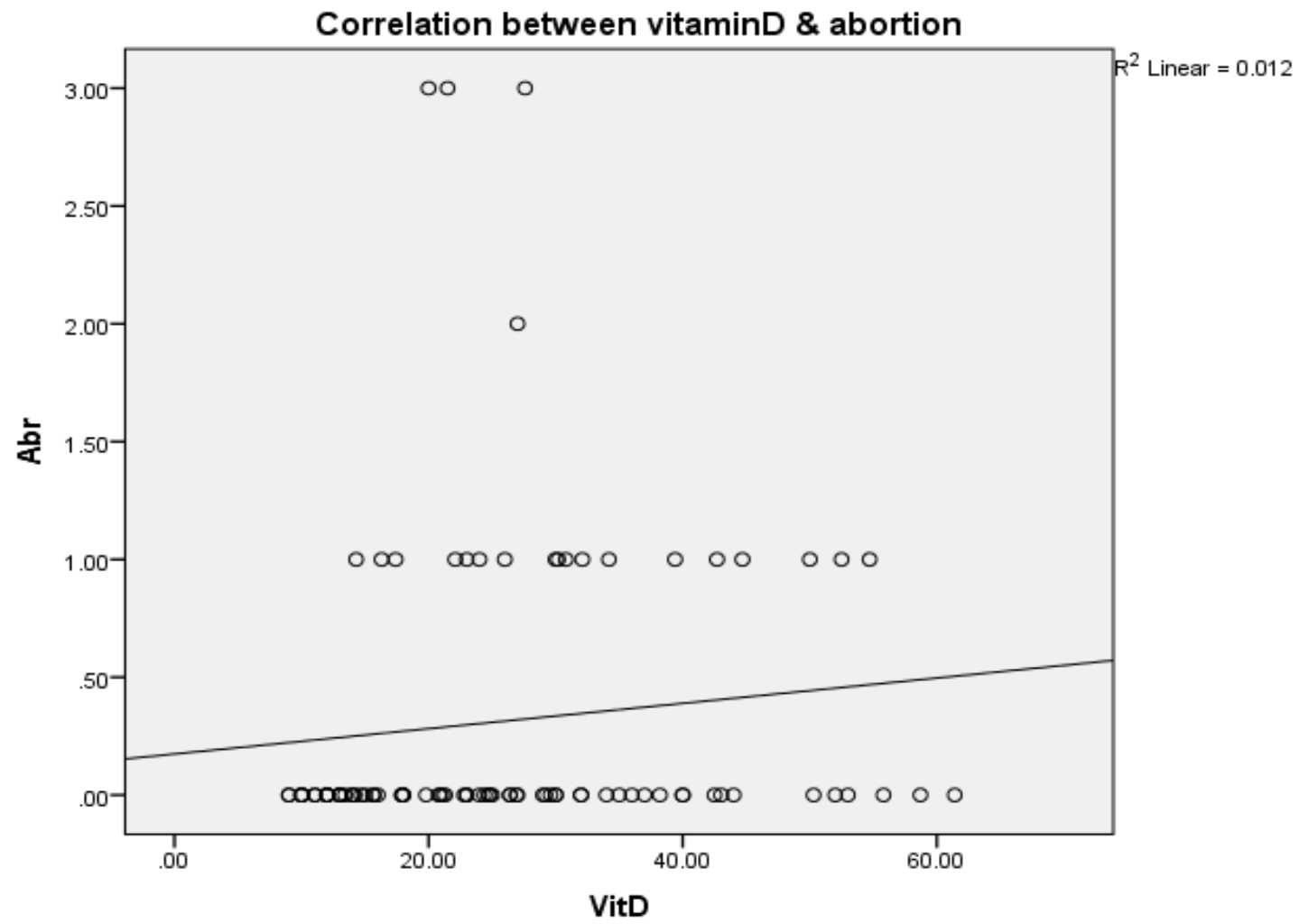


Figure (10):- Correlation between vitamin D \& MPV :

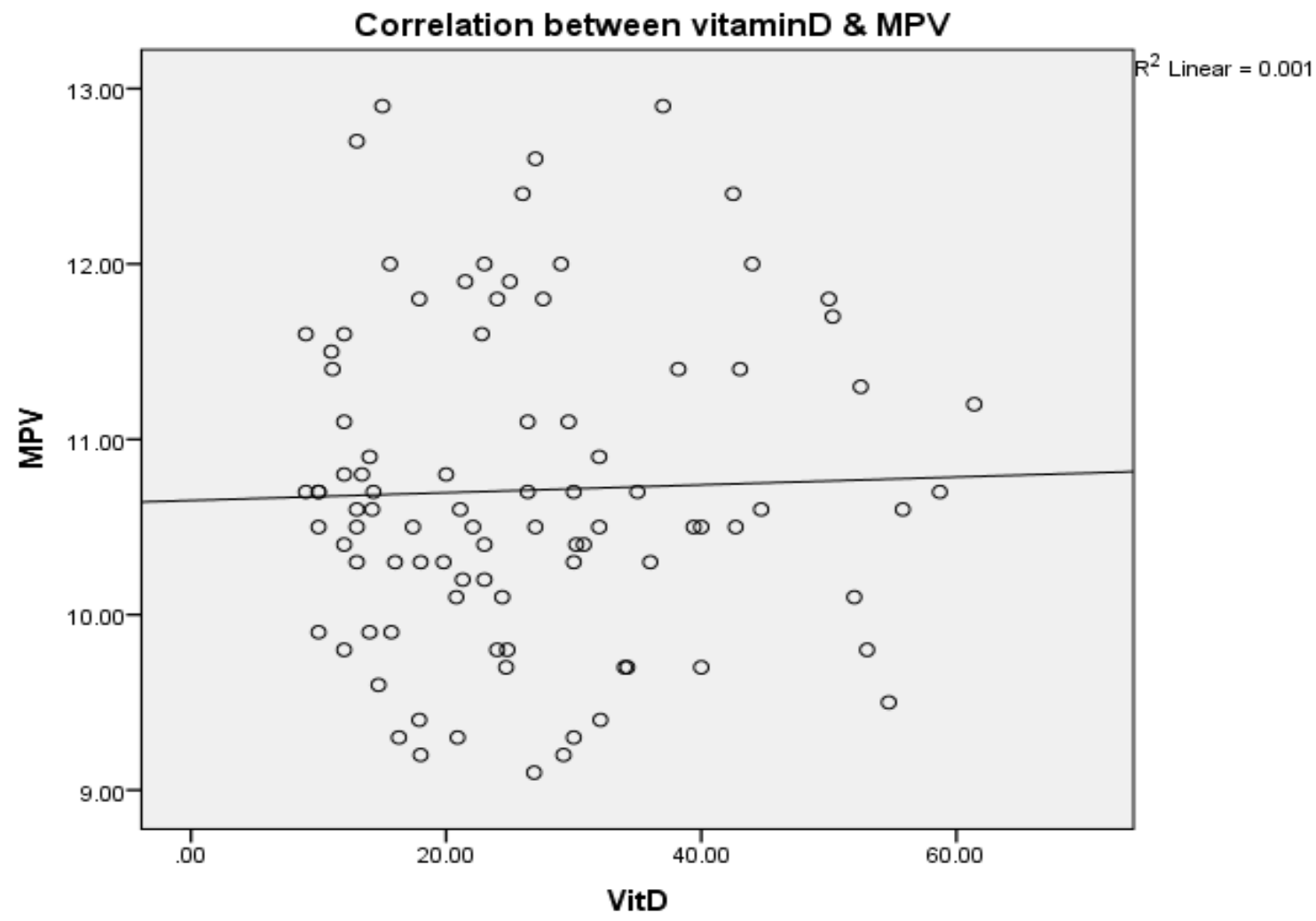

Figure (11):- Correlation between vitamin D \& HbA1C :

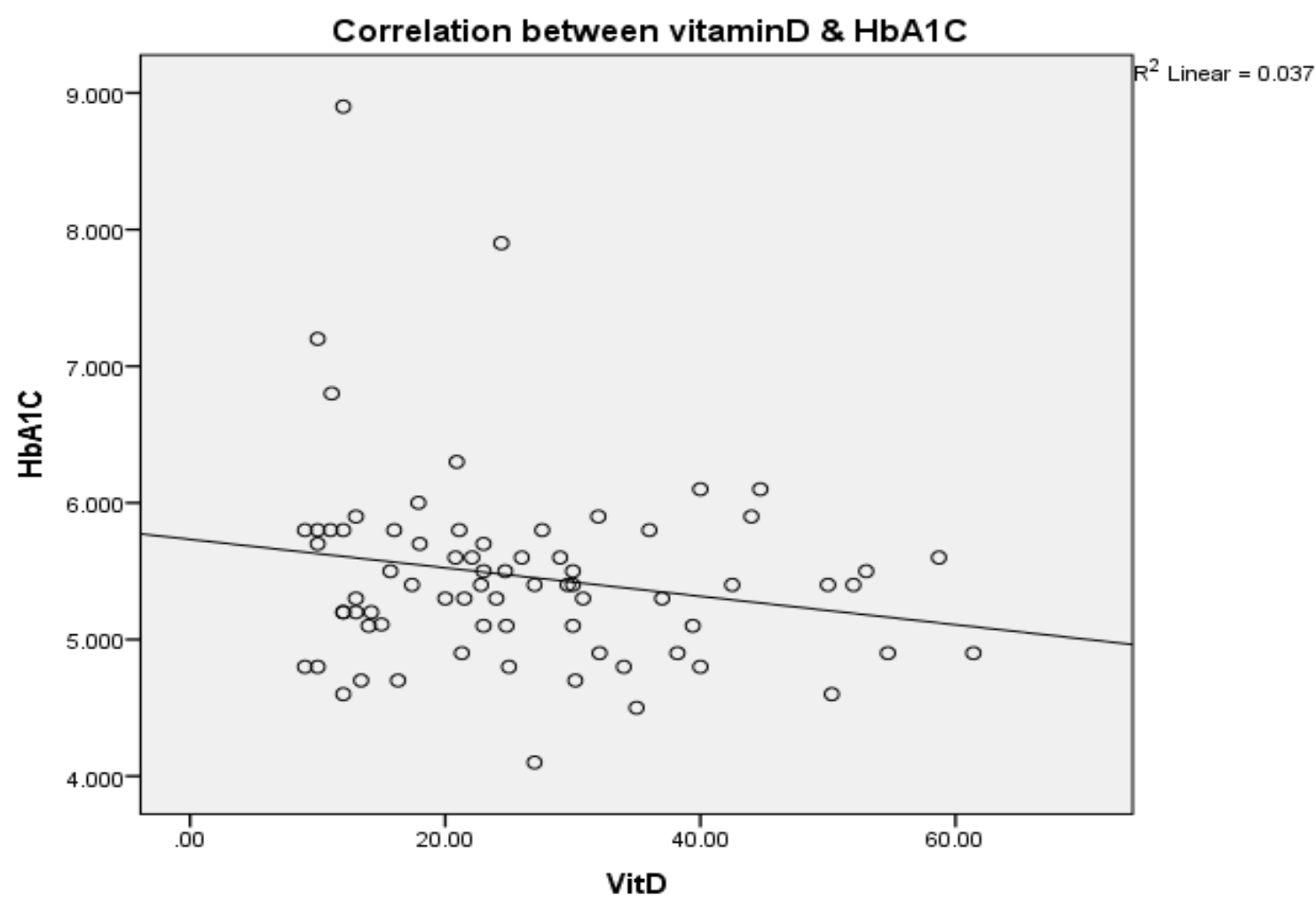


Figure (12):- Correlation between vitamin D \& GCT :

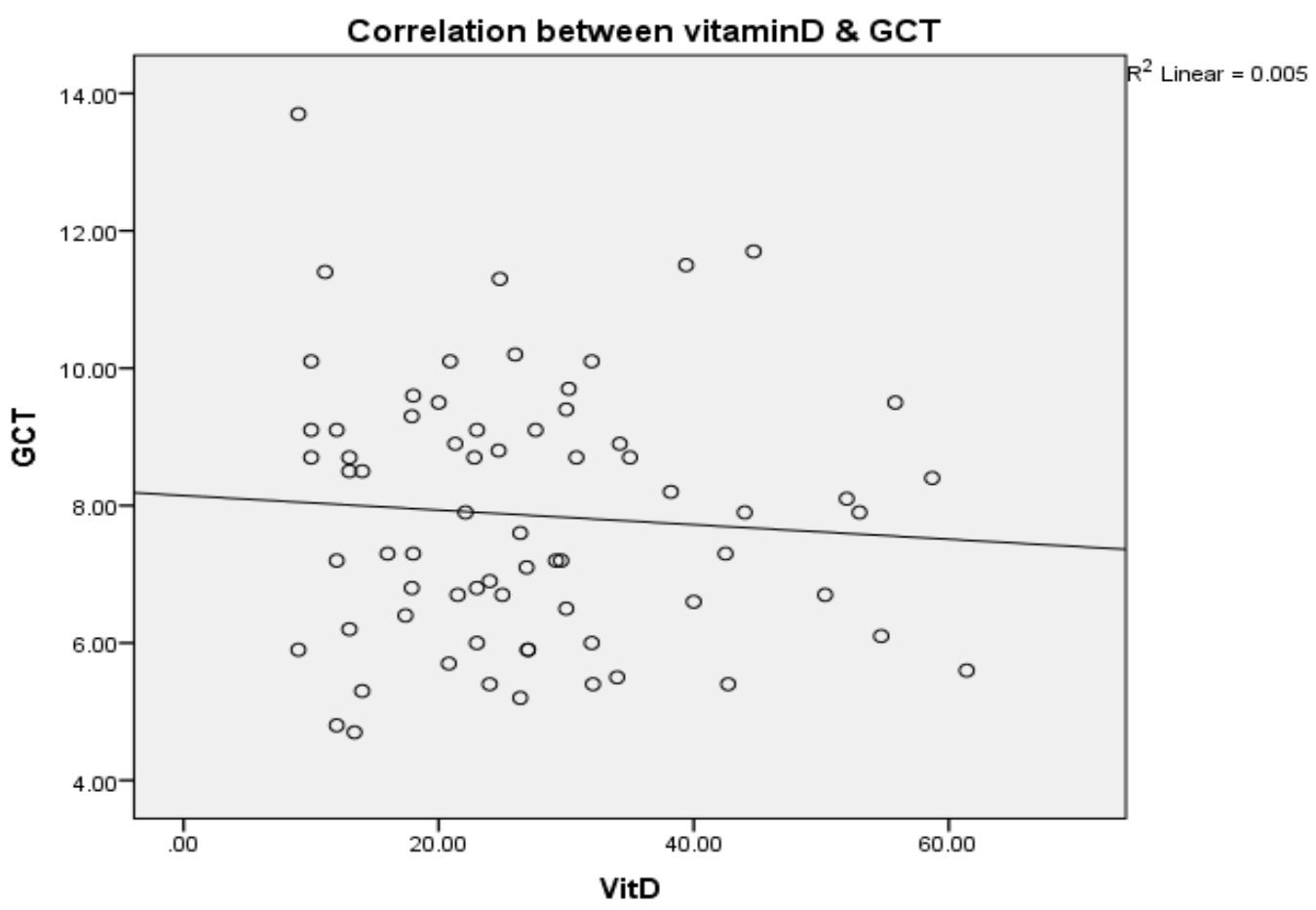

Figure (13):- Correlation between vitamin D \& GTTF :

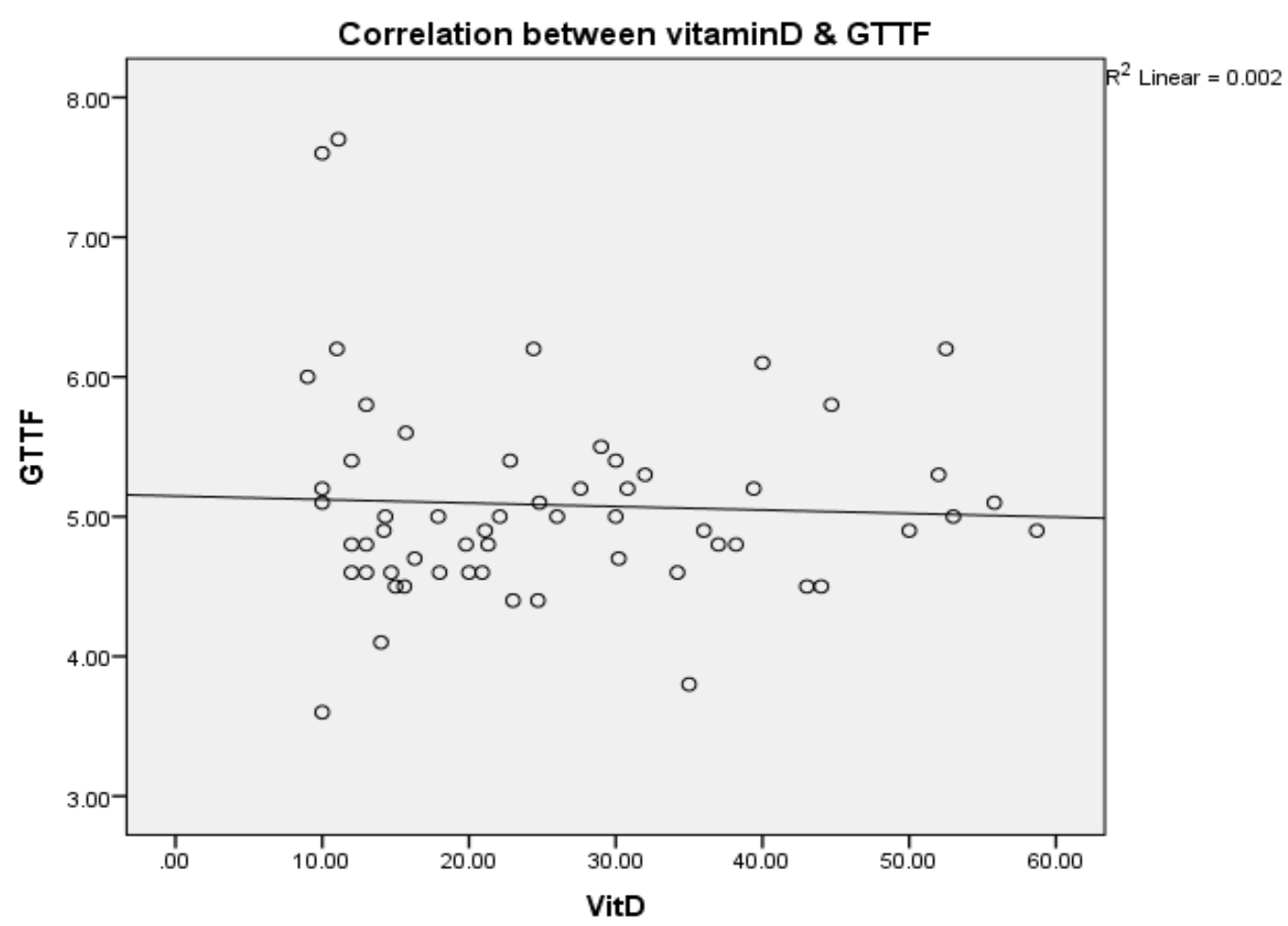


Figure (14):- Correlation between vitamin D \& GTT1 :

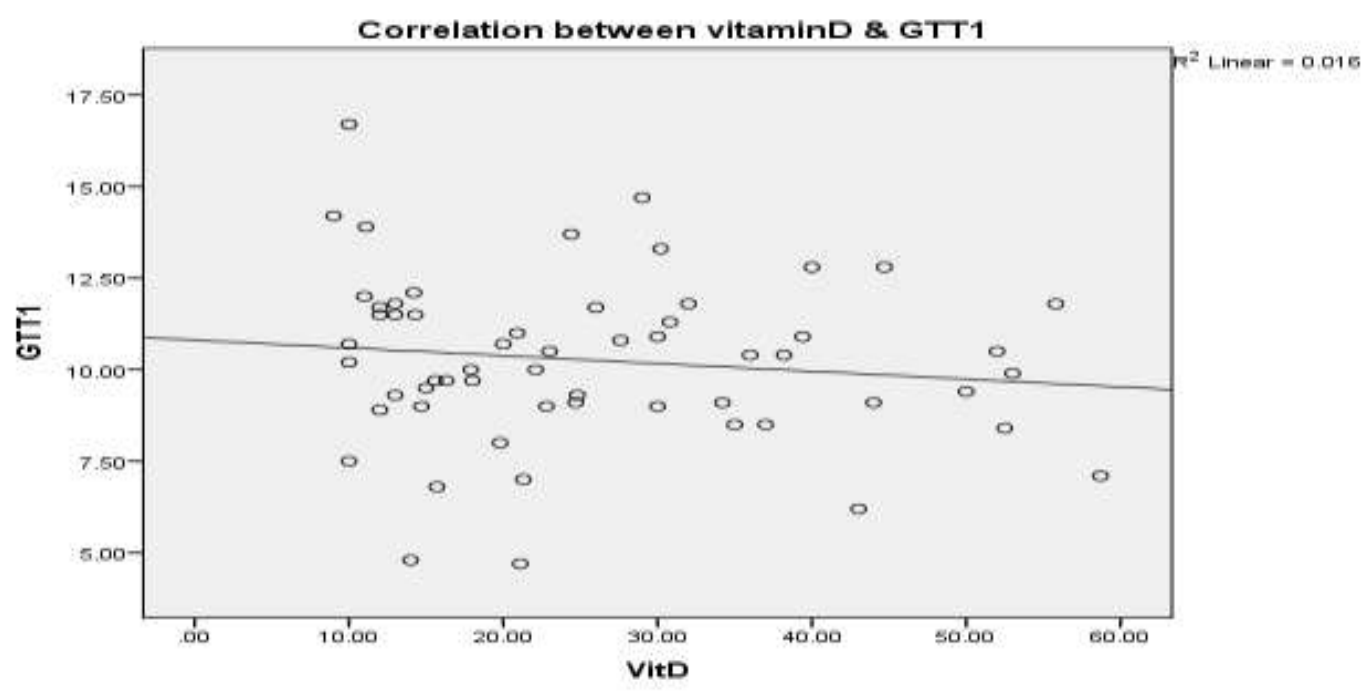

Figure (15):- Correlation between vitamin D \& GTT2 :

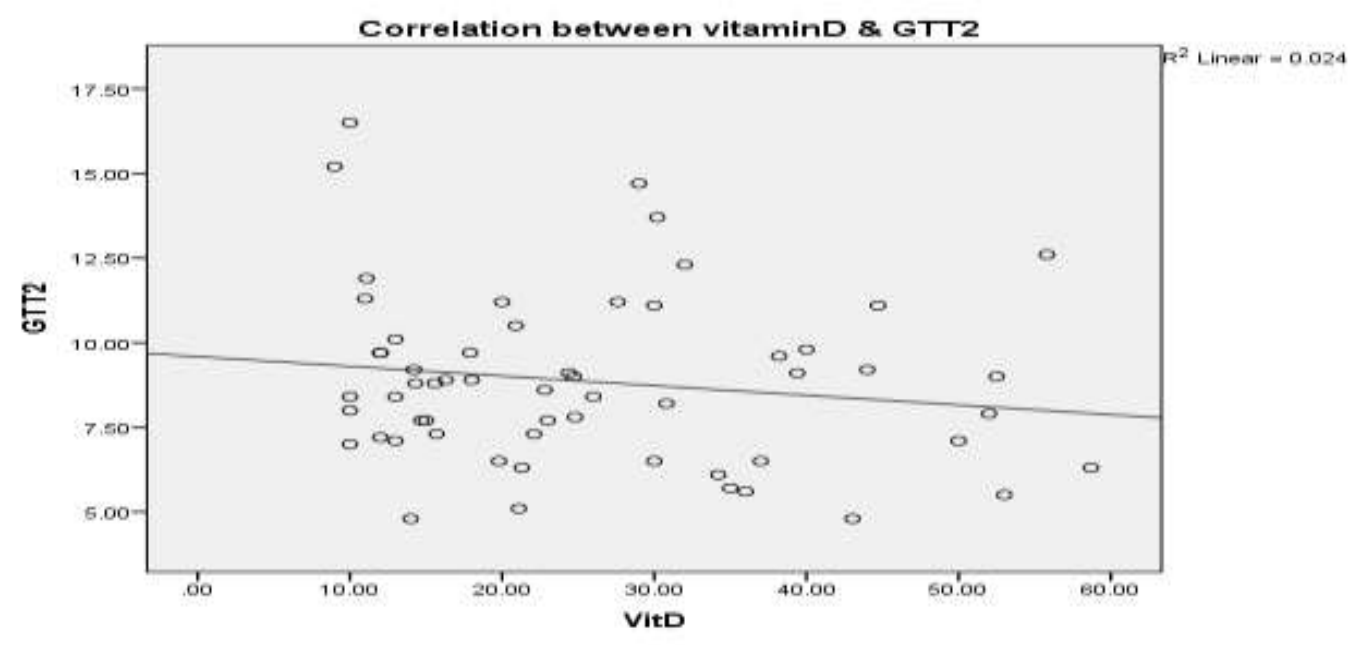

Figure (16):- Correlation between vitamin D \& GTT3 :

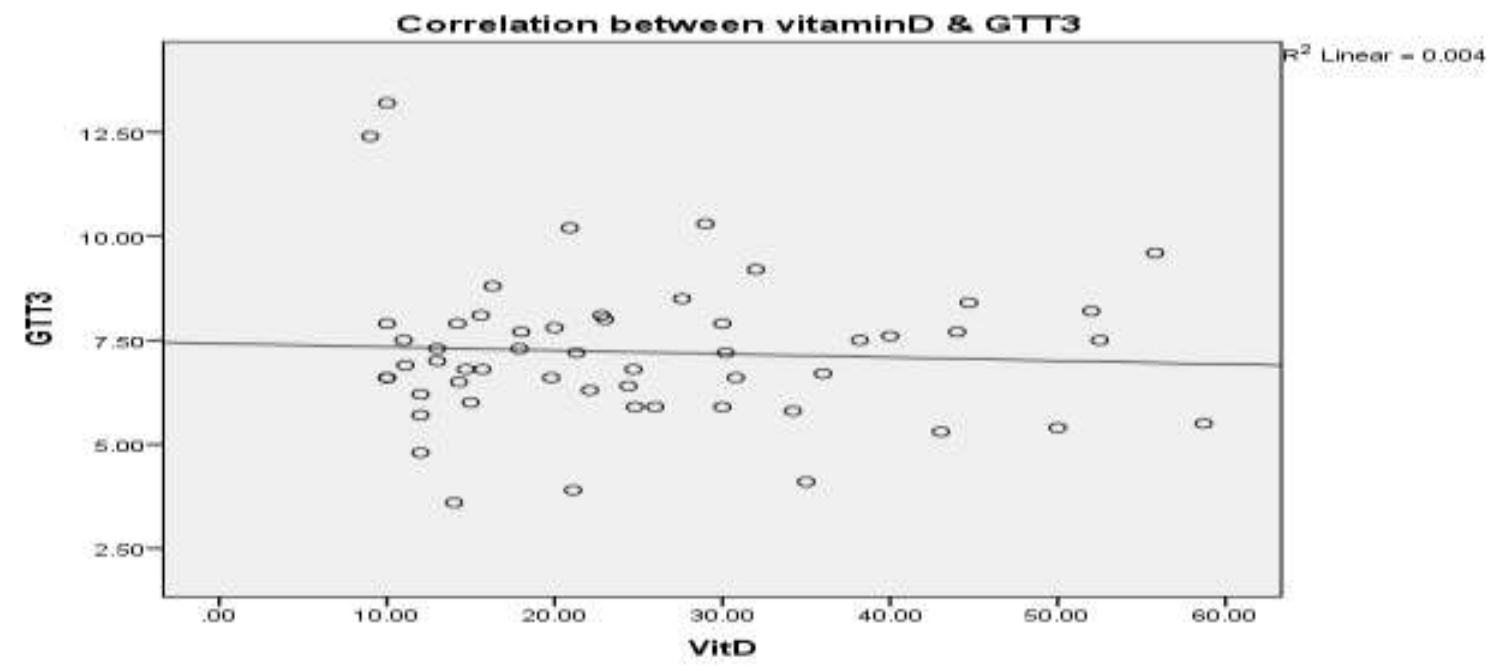




\section{Discussion:-}

92 pregnant women were recruited for this study which was aimed at measuring the vitamin D level in normal pregnant and gestational diabetic women.

400 pregnant women were screened at the ante natal clinic. 92 of the 400 women met the inclusion and exclusion criteria.

32 pregnant women were found to be diagnosed as GDM. They included women diagnosed as GDM for the first time and those who had GDM in a previous pregnancy. This was $34.78 \%$ of the total women recruited.

Since pregnancy is very vital stage of the future generation any condition which affects the health of a pregnant woman can have lasting implications on the health of the baby and its future (Burris and Camargo, 2014). Over the period of pregnancy, some women develop insulin resistance, which leads to impaired glucose tolerance (IGT) or gestational diabetes mellitus (GDM) (Senti et al., 2012, Lewis et al., 2010). GDM raises the risk of adverse outcomes for both mother and baby (Senti et al., 2012, Lewis et al., 2010). Several studies were conducted to detect GDM and its linked risk factors (63-65). Some of these studies provided evidence on the relation between vitamin D deficiency and developing GDM (Burris and Camargo, 2014). These relations were explained by the fact that vitamin D has essential role in the mechanism of glucose homeostasis and insulin sensitivity (Senti et al., 2012).

This study aimed to investigate vitamin D levels in gestational diabetic pregnant patients and their correlation with each other.

Regarding the relation between developing GDM and both age and BMI, the results of the current study revealed an increase in the risk of having GDM in older age women and higher BMI. This could be explained by the fact that women with high BMI are either obese or overweight, where these groups are at higher risk of developing GDM. Similar results were reported in a study conducted in Canada (2012) where GDM group had higher BMI than nonGDM group (71.3 \pm 18.4 vs $65.2 \pm 12.0 \mathrm{p}=0.0005)$ (Parlea et al., 2012). Also in Turkey, the authors reported significant older age and higher BMI among GDM group compared with non-GDM $(\mathrm{p}=0.002$, $\mathrm{p}<0.001)$ respectively (Zuhur et al., 2013).

Concerning vitamin D level, the findings of the current study showed no statistical difference between GDM group and non-GDM group. Similar results were reported in a USA study, where Baker et al reported no significant association between GDM and vitamin D level (Baker et al., 2012). In contrast, several studies confirmed this significant relation. In Iran (2010), Soheilykhah et al conducted a matched case control study among 54 pregnant women; they reported a significant lower vitamin D level in (83\%) GDM women compared with non-GDM (Soheilykhah et al., 2010). Parlea et al conducted a nested case-control study among 345 pregnant women (116 GDM \& 219 non-GDM) and they reported significant lower vitamin D serum level in GDM group (56.3 vs. 62.0 nmoV 1, P = 0.018) (Parlea et al., 2012). Also, in Turkey, Zuhur et al recognized significant increase in GDM cases among women who suffered from severe vitamin D deficiency (Zuhur et al., 2013). All these studies and other studies provided clear evidence of vitamin D being a risk factor in the development of GDM (Parlea et al., 2012). This variety in results could be attributed to the usage of different cut - off points and geographic variations.

Significant difference between GDM group and non-GDM group was observed in all laboratory investigation related to glucose measurements (GCT, GTTF, GTT1, GTT2, GTT3 and HbA1C). All the results were higher in the GDM group. These findings are consistent with the study from Korea, where Park et al reported significant difference between GDM group and non-GDM group regarding several glucose measurements (Park et al., 2014). Also Parildar et al from turkey reported significant difference between GDM group and non-GDM group regarding HbA1c $(\mathrm{p}=0.004)$ and Fasting serum glucose ( $\mathrm{p}<0.01)$ (Parildar et al., 2013). And in Egypt, El Lithy et al reported significant negative correlation between the level of vitamin D and both HbA1C and fasting blood sugar levels. This could be explained by the fact that vitamin D plays an important role in blood glucose level through several mechanisms such as, regulation of plasma calcium levels, which control insulin synthesis and secretion, improves insulin sensitivity of the target cells, improves $\beta$-cell function and keeps them away from immune attacks (El Lithy et al., 2014).

The findings revealed increase in BMI when there is decrease in vitamin D level. This result consists with a previous study in USA, a nest case control among 180 pregnant women; they reported a small negative correlation between BMI and vitamin D (Baker et al., 2012). 
After distributing the 92 female patients into four quartiles depending on vitamin D level, they were arranged from lowest value to highest value of vitamin D. We found that $30.4 \%$ of the fourth quartile (Q4) was GDM while $47.8 \%$ of the first quartile (Q1) was GDM with no statistical significance. No statistical significance was found between quartiles $1 \& 4$ regarding all other variables. In a study conducted in china in 2017, there was a statistically significant difference in developing GDM between Q4 and Q1. 26.1\% women in Q1 developed GDM and 3.9\% women developed GDM from Q4. Q1 being low vitamin D and Q4 being high vitamin D levels (Xu et al., 2017). Our study was in consensus with this Chinese study regarding obesity being an additional risk factor in the development of GDM. We found statistical significance with higher BMI being associated with lower vitamin D and higher incidence of GDM (Table 1, 2 \& 2A).

In our study $9.78 \%$ of the subjects had normal vitamin D with $90.22 \%$ being vitamin D deficient. Other studies conducted in Saudi Arabia showed results of $100 \%$ deficiency in vitamin d level (Dr. Ebtehal Solaiman Al-Mogbel, 2012).

The percentage of GDM in our study is $9.78 \%$, in Jeddah, GDM affects $12.5 \%$ of pregnancies, which is much higher than Dammam 11\% and Riyadh 10.3\% (Sabah M. Hassan1, 2015, Al-Rowaily, 2010).

\section{Conclusion:-}

Our study was not able to conclude vitamin D as being a significant risk factor. This might be due to the limitation as regards the number of subjects recruited. GDM like many other conditions is a result of interplay of multiple risk factors, like obesity, age and other vitamin and mineral deficiencies (Xu et al., 2017, Siddiqui et al., 2014)

This conclusion gains strength due to the presence of GDM among significant number of women with normal vitamin D levels in our study (3 out of 9,33.33\%). Further studies with higher number of subjects may provide us with results consistent with other studies. Optimizing the vitamin D levels in females of reproductive age group is highly recommended in order to produce a robust, and healthy nation.

\section{Refrences:-}

1. AL-ROWAILY, M. A. 2010. Predictors of gestational diabetes mellitus in a highparity community in Saudi Arabia EasternMediterraneanHealthJournal 16.

2. ALFADHLI, E. M., OSMAN, E. N., BASRI, T. H., MANSURI, N. S., YOUSSEF, M. H., ASSAAEDI, S. A. \& ALJOHANI, B. A. 2015. Gestational diabetes among Saudi women: prevalence, risk factors and pregnancy outcomes. Ann Saudi Med, 35, 222-30.

3. BAKER, A. M., HAERI, S., CAMARGO, C. A., JR., STUEBE, A. M. \& BOGGESS, K. A. 2012. Firsttrimester maternal vitamin D status and risk for gestational diabetes (GDM) a nested case-control study. Diabetes Metab Res Rev, 28, 164-8.

4. BODNAR, L. M., PLATT, R. W. \& SIMHAN, H. N. 2015. Early-pregnancy vitamin D deficiency and risk of preterm birth subtypes. Obstet Gynecol, 125, 439-47.

5. BURRIS, H. H. \& CAMARGO, C. A., JR. 2014. Vitamin D and gestational diabetes mellitus. Curr Diab Rep, $14,451$.

6. DR. EBTEHAL SOLAIMAN AL-MOGBEL, M., SBFM, ABFM 2012. Vitamin D status among Adult Saudi Females visiting Primary Health Care Clinics

7. EL LiTHY, A., ABDElla, R. M., El-FAISSAL, Y. M., SAYED, A. M. \& SAMIE, R. M. 2014. The relationship between low maternal serum vitamin D levels and glycemic control in gestational diabetes assessed by HbA1c levels: an observational cross-sectional study. BMC Pregnancy Childbirth, 14, 362.

8. HOLLIS, B. W. \& WAGNER, C. L. 2017a. New insights into the vitamin D requirements during pregnancy. Bone Res, 5, 17030.

9. HOLLIS, B. W. \& WAGNER, C. L. 2017b. Vitamin D supplementation during pregnancy: Improvements in birth outcomes and complications through direct genomic alteration. Mol Cell Endocrinol, 453, 113-130.

10. HOSPITAL, K. E. M. 2016. SCREENING FOR AND TREATMENT OF VITAMIN D DEFICIENCY IN PREGNANCY. WOMEN AND NEWBORN HEALTH SERVICE, CLINICAL GUIDELINES OBSTETRICS AND MIDWIFERY.

11. JANYNE ALTHAUS, M. August 2011. Vitamin D and pregnancy: 9 things you need to know. $O B G$ Management Vol. 23 No. 8, 30-36

12. LEWIS, S., LUCAS, R. M., HALLIDAY, J. \& PONSONBY, A. L. 2010. Vitamin D deficiency and pregnancy: from preconception to birth. Mol Nutr Food Res, 54, 1092-102. 
13. MCDOnNell, S. L., BAgGerly, K. A., BAgGerly, C. A., AliAnO, J. L. \& FRENCH, C. B. 2017. Maternal $25(\mathrm{OH}) \mathrm{D}$ concentrations $>/=40 \mathrm{ng} / \mathrm{mL}$ associated with $60 \%$ lower preterm birth risk among general obstetrical patients at an urban medical center. 12, e0180483.

14. MUTLU, N., ESRA, H., BEGUM, A., FATMA, D., ARZU, Y., YALCIN, H., FATIH, K. \& SELAHATTIN, K. 2015. Relation of maternal vitamin D status with gestational diabetes mellitus and perinatal outcome. Afr Health Sci, 15, 523-31.

15. PARILDAR, H., DOGRUK UNAL, A., AKSAN DESTELI, G., CIGERLI, O. \& GUVENER DEMIRAG, N. 2013. Frequency of Vitamin D deficiency in pregnant diabetics at Baskent University Hospital, Istanbul. Pak $J$ Med Sci, 29, 15-20.

16. PARK, S., YOON, H. K., RYU, H. M., HAN, Y. J., LEE, S. W., PARK, B. K., PARK, S. Y., YIM, C. H. \& KIM, S. H. 2014. Maternal vitamin D deficiency in early pregnancy is not associated with gestational diabetes mellitus development or pregnancy outcomes in Korean pregnant women in a prospective study. $J$ Nutr Sci Vitaminol (Tokyo), 60, 269-75.

17. PARlEA, L., BROMBERG, I. L., FEIG, D. S., VIETH, R., MERMAN, E. \& LIPSCOMBE, L. L. 2012. Association between serum 25-hydroxyvitamin D in early pregnancy and risk of gestational diabetes mellitus. Diabet Med, 29, e25-32.

18. PlESKACOVA, A., BARTAKOVA, V., PACAL, L., KURICOVA, K., BELOBRADKOVA, J., TOMANDL, J. \& KANKOVA, K. 2015. Vitamin D Status in Women with Gestational Diabetes Mellitus during Pregnancy and Postpartum. Biomed Res Int, 2015, 260624.

19. QARI, F. A. 2013. Practical Approach for the Prevention and Management of Vitamin D Deficiency in Adults. Journal of Family Medicine and Primary Care, 2, 315-318.

20. SABAH M. HASSAN1, ARCHANA P. IYER3 AND FAHAD A. AL-ABBASI2 2015. Screening for Glucokinase (GCK) Gene Mutation in Gestational Diabetes Women in Western Region of Saudi Arabia British Journal of Medicine \& Medical Research

21. SADAT-ALI, M. A., ABDULMOHSEN; AL-TURKI, HAIFA; AL-MULHIM, FATMA; AL-ALI, AMEIN. 2009. Vitamin D levels in healthy men in eastern Saudi Arabia. Annals of Saudi Medicine; .

22. SENTI, J., THIELE, D. K. \& ANDERSON, C. M. 2012. Maternal vitamin D status as a critical determinant in gestational diabetes. J Obstet Gynecol Neonatal Nurs, 41, 328-38.

23. SHAHGHEIBI, S., FARHADIFAR, F. \& POUYA, B. 2016. The effect of vitamin D supplementation on gestational diabetes in high-risk women: Results from a randomized placebo-controlled trial. J Res Med Sci, 21, 2.

24. SIDDIQUI, K., BAWAZEER, N. \& SCARIA JOY, S. 2014. Variation in Macro and Trace Elements in Progression of Type 2 Diabetes. The Scientific World Journal, 2014, 461591.

25. SOHEILYKHAH, S., MOJIBIAN, M., RASHIDI, M., RAHIMI-SAGHAND, S. \& JAFARI, F. 2010. Maternal vitamin D status in gestational diabetes mellitus. Nutr Clin Pract, 25, 524-7.

26. URRUTIA-PEREIRA, M. \& SOLÉ, D. 2015. Vitamin D deficiency in pregnancy and its impact on the fetus, the newborn and in childhood. Revista Paulista de Pediatria, 33, 104-113.

27. XU, C., MA, H. H. \& WANG, Y. 2017. Maternal Early Pregnancy Plasma Concentration of 25Hydroxyvitamin D and Risk of Gestational Diabetes Mellitus. Calcif Tissue Int.

28. ZHOU, S. S., TAO, Y. H., HUANG, K., ZHU, B. B. \& TAO, F. B. 2017. Vitamin D and risk of preterm birth: Up-to-date meta-analysis of randomized controlled trials and observational studies. J Obstet Gynaecol Res, 43, 247-256.

29. ZUHUR, S. S., EROL, R. S., KUZU, I. \& ALTUNTAS, Y. 2013. The relationship between low maternal serum 25-hydroxyvitamin D levels and gestational diabetes mellitus according to the severity of 25-hydroxyvitamin D deficiency. Clinics, 68, 658-664. 